\title{
Synthesis of polyaminophosphonic acid-functionalized poly(glycidyl methacrylate) for the efficient sorption of La(III) and Y(III)
}

\author{
Ahmed A. Galhoum ${ }^{\mathrm{a}, \mathrm{b}, *}$, Emad A. Elshehy ${ }^{\mathrm{b}}$, Dina A. Tolan ${ }^{\mathrm{c}}$, Ahmed M. El-Nahas ${ }^{\mathrm{c}}$, \\ ${ }^{a}$ Faculty of Bioscience and Applied Chemistry, Hosei University, 3-7-2, Kajino-chou, Koganei, Tokyo, 184-8584, Japan \\ ${ }^{\mathrm{b}}$ Nuclear Materials Authority, P.O. Box 530, El-Maadi, Cairo, Egypt \\ ${ }^{\mathrm{c}}$ Department of Chemistry, Faculty of Science, Menoufia University, Shebin El-Kom, Egypt \\ ${ }^{\mathrm{d}}$ Department of Chemistry, Hokkaido University, Sapporo 060-0810, Japan \\ ${ }^{\mathrm{e}}$ Refining Division, Egyptian Petroleum Research Institute, Nasr City, Cairo 11727, Egypt \\ ${ }_{\mathrm{f}}^{\mathrm{f}}$ Institut Mines Telecom - Mines Alès, C2MA, Univ. Montpellier, 6 avenue de Clavières, F-30319 Alès cedex, France
} Tetsuya Taketsugu $^{\mathrm{d}}$, Kaoru Nishikiori ${ }^{\mathrm{a}}$, Takaya Akashi ${ }^{\mathrm{a}}$, Asmaa S. Morshedy ${ }^{\mathrm{e}}$, Eric Guibal ${ }^{\mathrm{f}, *}$

\section{H I G H L I G H T S}

- PGMA was functionalized with aminophosphonic groups to sorb rare earth elements.

- XPS, FTIR and molecular modeling were applied for characterizing metal binding.

- Sorption isotherms and uptake kinetics are modeled for La(III) and Y (III) recovery.

- Metal desorption and sorbent recycling are highly efficients.

- The treatment of monazite leachate is discussed in terms of affinity for REEs.
G R A P H I C A L A B S T R A C T
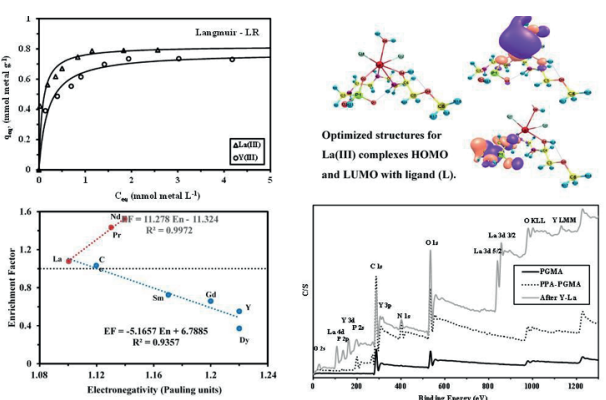

\section{A B S T R A C T}

Keywords:

Rare earth element

Glycidyl methacrylate

Phosphomethylation

Aminoalkylphosphonic group

Sorption isotherms

Uptake kinetics

Metal desorption

Sorbent recycling
After synthesis of parent PGMA micro-particles by dispersion polymerization method, diethylenetriamine (DETA) is grafted on the polymer (DETA-PGMA). In the last step, methylene phosphonic groups are grafted on DETA-PGMA by reaction of phosphonic acid groups onto amine functions in the presence of formaldehyde to produce polyaminophosphonic acid sorbent (PPA-PGMA). The sorbent is characterized by elemental analysis, FTIR spectrometry, XPS, XRD, TG-TDA and SEM-EDX analyses. The sorption properties of the material are tested for the sorption of $\mathrm{La}(\mathrm{III})$ and $\mathrm{Y}(\mathrm{III})$ : the effect of $\mathrm{pH}$ on sorption performance is investigated before studying uptake kinetics, sorption isotherms (and thermodynamics), metal desorption and sorbent recycling. Maximum sorption capacities reach up to $0.79 \mathrm{mmol} \mathrm{La} \mathrm{g}^{-1}$ and $0.73 \mathrm{mmol} \mathrm{Y} \mathrm{g}^{-1}$ at $\mathrm{pH} 5$ (optimum initial pH value). Sorption isotherms are characterized by a saturation plateau: the Langmuir equation fits well data. The sorption on micron-sized particles is fast and equilibrium is reached within 3-4 h: the kinetic profiles are modelled by the Crank equation (resistance to intraparticle diffusion) though the pseudo-first order rate equation fits well experimental data. Nitric acid $(0.5 \mathrm{M})$ solutions can be used for metal recovery and the sorbent is re-used for at

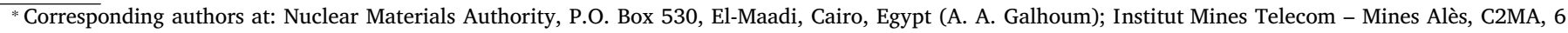
avenue de Clavières, F-30319 Alès cedex, France (E. Guibal).

E-mail addresses: Galhoum_nma@yahoo.com (A.A. Galhoum), Eric.Guibal@mines-ales.fr (E. Guibal).
} 
least 6 cycles of sorption and desorption with limited decrease in performance (less than 7\%). The sorbent has a preference at $\mathrm{pH} 5$ for $\mathrm{La}$ (III) vs. Y(III) but the selectivity coefficient is not high enough for potentiating the selective separation of the two metals.

\section{Introduction}

The formal group of rare earth elements (REEs; i.e., the lanthanide series) is generally completed by scandium and yttrium because these elements are frequently associated to REEs-enriched ores; in addition, they have very similar chemical properties (close electronic configuration, trivalent form as the most stable in solution, etc.). Though the classification between the REEs remains debatable it is generally accepted that they can be divided in two groups: (a) light REES (LRREs) that includes La to Dy elements, and (b) heavy REEs (HREEs) including Ho to Lu elements plus Y element [1-5]. They are considered strategic resources because they are widely used in advanced technologies such as electronic and communication devices, high performance alloys and magnets, high performance glasses, ceramics and catalysts. The very close chemical properties of these elements make their selective separation an important industrial challenge that can also explains that REE industry is a strategic industrial field. The balance between production and consume of REEs at the world level and its uses for strategic applications make their production, recovery and recycling an important issue with geopolitical and economic dimensions.

Many countries and international organizations have then promoted incentive politics for their recycling from spent materials and devices and for the valorization of low grade ores (including sub-product from primary resources, such as phosphate rock conversion into phosphoric acid and phosphogypsum) [1,2,5]. Lanthanum is one of the most abundant rare earth elements; it is present in rare earth minerals such as cerite, allanite, etc. Monazite and bastnasite minerals are the principal ores for lanthanum extraction since its content may reach up to $25 \%$ and $38 \%$, respectively $[2,6]$.

A wide range of methods have been designed for the recovery of metals (including REEs) from water including chemical precipitation, and flocculation. However, these methods are frequently not competitive, especially for removing REEs from dilute solutions [1,5-8].
Sorption processes using ion-exchange and chelating resins are more appropriate for concentrating and separating metals ions from dilute effluents, because they are highly efficient and environmental friendly [9-11]. Glycidyl methacrylate (GMA), bearing both vinyl and epoxy functions, is a very useful reactive monomer that meets the requirements for post-polymerization modification: new functional groups (such as amine, carboxylic groups, etc.) can be readily grafted by ringopening reaction. It is also a low-cost reagent that is widely used for the industrial production of epoxy functional methacrylic resins (precursors for manufacturing coatings and adhesives) $[12,13]$. In chelating resins, the functional group atoms that are most frequently used consist of nitrogen (i.e., $\mathrm{N}$ present in amines, azo groups, amides, nitriles), oxygen (i.e., O present in carboxylic, hydroxyl, phenolic, ether, carbonyl), phosphoryl groups (i.e., $\mathrm{P}$ present in $\mathrm{P}-\mathrm{O}$ or $\mathrm{P}=\mathrm{O}$ groups), and sulfur (i.e., $S$ present in thiols, thiocarbamates, thioethers). Usually, the anchored molecules contain nitrogen, oxygen or sulfur atoms, or a combination of them, acting as the basic centers that complex cations and allow selective extraction [14-19]. The $\alpha$-aminophosphonate-based compounds are among the most useful organophosphorus derivatives; they have attracted increasing attention because of their biological properties and potential applications in pharmacological and agrochemical fields $[20,21]$. These organophosphorus compounds and their derivatives are also known as good metal-complexing agents for various transition metals in diagnostic and therapeutic applications [22], but also as industrial chemicals in water treatment, metal extraction, or pollution control [23-25], by analogy with synthetic resins [26] and liquid/liquid extractants [27-29]. Recently, the affinity of phosphate groups for uranium has been used for elaborating an inorganic/organic composite (based on the simple and readily encapsulation of microparticles of a mineral rock with chitosan) [30].

Though an extensive literature exists on the recovery of REEs using amine-based sorbents and aminophosphonic-grafted resins, the present study brings a very complete overview on a new sorbent for rare earth<smiles>C=C(C)C(=O)OCC1CO1</smiles>

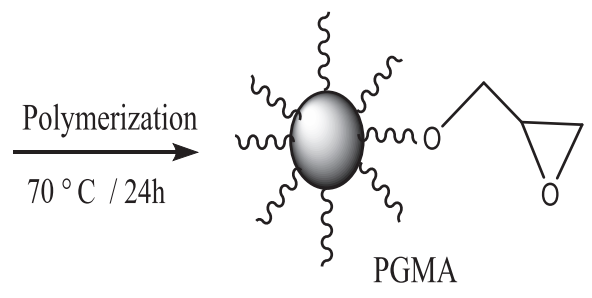

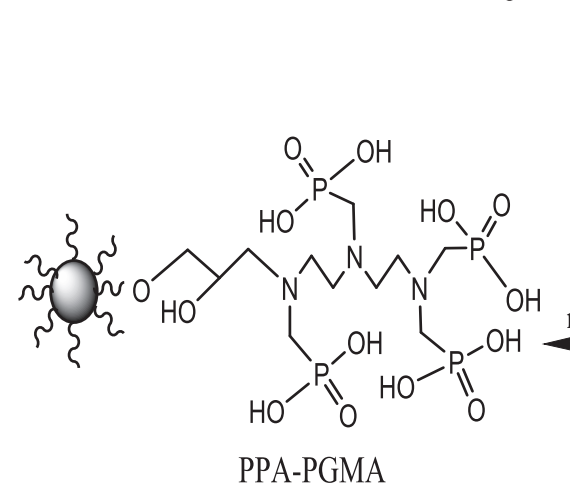

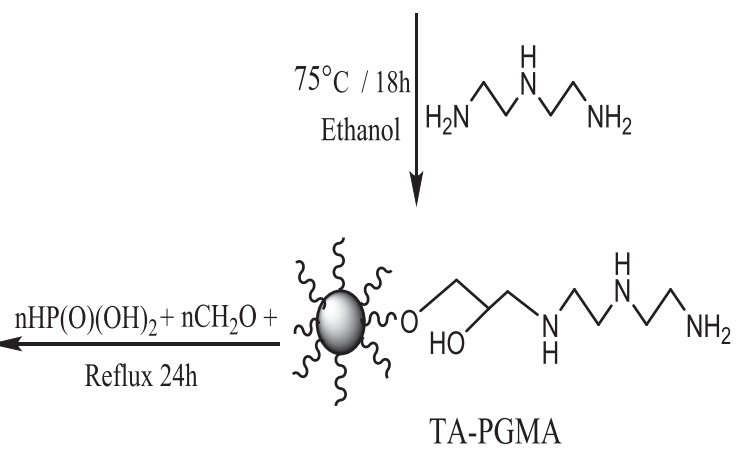

Fig. 1a. Proposed scheme for the synthesis of polyaminophosphonic acid-functionalized poly(glycidyl methacrylate) (PGMA): PPA-PGMA. 
element recovery; including both characterization aspects, evaluation of sorption performances and application to the treatment of alkaline leachate of Egyptian monazite (after $\mathrm{pH}$ adjustment).

In this work, the sorption of La(III) and Y(III) (as representative of LREEs, light REEs and HREEs, heavy REEs, respectively) has been investigated using a new micron-sized sorbent obtained by bi-functionalization of polyglycidyl methacrylate (PGMA) with amino groups and aminoalkyl-phosphonic ligand (PPA-PGMA). The physicochemical structure and properties of the sorbent are first characterized by elemental analysis, SEM-EDX, FTI R, XRD, TGA, XPS, pH $\mathrm{PZC}_{\text {. Sorption }}$ properties are studied considering the effect of $\mathrm{pH}$, the uptake kinetics, the sorption isotherms, the thermodynamic parameters. Molecular calculations (density functional theory, DFT) were used for suggesting the most probable complexes formed between functional groups and target REEs, in complement to analytical methods. Finally, the regeneration and recycling of the material and its reuse for successive sorption/desorption cycles are carried out. The sorbent was finally tested for recovery of metals from leachates of monazite. Monazite is an orthophosphate ore containing high concentrations of REEs and thorium. This is the typical compound of black sands. La(III) and Y(III) being with $\mathrm{Ce}(\mathrm{III})$ and $\mathrm{Nd}(\mathrm{III})$ the most important elements founds in the acidic leachates of Egyptian monazite, the study was focused on La (I I I Orepresenting LREEs) and Y(I I I (representing HREE family). Though Y(III) is not a formal member of REEs, its physical and chemical properties are very similar to the elements belonging to the series Dy (I I I )-Er(I I IQe(I I I can be recovered by readily oxidation (to form $\mathrm{Ce}^{4+}$ ) and precipitation. $\mathrm{Nd}(\mathrm{III})$ has received a great attention in terms of selective sorption; this study will contribute to evaluate the possibility to separate $\mathrm{La}(\mathrm{III})$ from $\mathrm{Y}(\mathrm{III})$ for this kind of complex media.

\section{Material and methods}

\subsection{Materials}

Glycidyl methacrylate (GMA), diethylenetriamine (DETA), formaldehyde solution (37\%), polyvinylpyrrolidone (PVP K-30), 2,2-azobisisobutyronitrile (AIBN), and ethanol (99.5\%) were purchased from Wako Chemical Co. Ltd. (Japan). Phosphorous acid was supplied by Sigma-Aldrich (Darmstadt, Germany). $\mathrm{LaCl}_{3}$ and $\mathrm{YCl}_{3}$ salts were purchased from Sigma-Aldrich. Stock solutions of La(III), and Y(III)ions were prepared by mineralization of the corresponding salts in concentrated $\mathrm{HCl}$ under heating; working solutions were diluted from stock solutions with demineralized water to a final c oncentration of $1000 \mathrm{mg} \mathrm{L}^{-1}$. All other chemicals were obtained from Prolabo (France); they were used as received.

\subsection{Synthesis of polyaminophosphonic acid-PGMA (PPA-PGMA)}

Fig. 1a schematically described the different steps involved in the synthesis of polyaminophosphonic acid-functionalized polyglycidyl methacrylate (PGMA) (i.e., PPA-PGMA), and the tentative chemical structure of the sorbent. The PGMA microspheres were produced using the dispersion polymerization as follows: the dispersion medium was first prepared by dissolving PVP K-30 (3 g) into $90 \mathrm{~g}$ of ethanol/water solution (90:10) in a $250 \mathrm{~mL}$ four-necked flask. The polymerization initiator (AIBN, $0.2 \mathrm{~g}$ ) was dispersed in the monomer phase (GMA, $10 \mathrm{~g}$ ) before being transferred into the dispersion medium. The reactor was purged with $\mathrm{N}_{2}$ for $30 \mathrm{~min}$ (to remove gas phase and dissolved $\mathrm{O}_{2}$ ). Next, the flask $\mathrm{w}$ as $\mathrm{m}$ aintained at $70{ }^{\circ} \mathrm{C}$ for $24 \mathrm{~h}$ u nder mechanical stirring $(120 \mathrm{rpm})$ and reflux condensation $[12,13]$. The resulting microspheres (PGMA, (i)) were centrifuged and washed several times with deionized water and ethanol before being dried under vacuum at ambient temperature. In the next step, the product (i) was suspended in $20 \mathrm{~mL}$ ethanol before adding DETA $(12 \mathrm{~mL})$, the mixture was stirred under reflux for $18 \mathrm{~h}$ [13]: the product (ii) a minated P GMA (or TAPGMA) was recovered by filtration a nd $\mathrm{w}$ ashed. I $\mathrm{n} t$ he $\mathrm{l}$ ast step, phosphorous acid $(5 \mathrm{~g})$ was dissolved in $100 \mathrm{~mL}$ of water and $\mathrm{HCl}$ (1:1, $\mathrm{v} / \mathrm{v}$ ). After addition of $1 \mathrm{~g}$ of the product (ii), the mixture was heated to reflux in a $200 \mathrm{~mL}$ three-necked flask (with thermometer, condenser, and dropping funnel) and $20 \mathrm{~mL}$ of formaldehyde solution was added dropwise for $1 \mathrm{~h}$. The mixture was kept at reflux temperature for 24 additional hours. The final product polyaminophosphonic acid-functionalized PGMA (PPA-PGMA) was filtered and extensively washed successively with ethanol and water. Finally, the sorbent was dried at $80^{\circ} \mathrm{C}$ for $24 \mathrm{~h}[16]$.

\subsection{Characterization of materials}

The elemental analysis was performed on a Micro Corder JM10 (JScience Lab Co., Ltd., Kyoto, Japan). Phosphorus content was specifically analyzed after mineralization using sulfuric acid/nitric acid digestion $[31,32]$. The FT-IR spectra were directly obtained (i.e., without conditioning under $\mathrm{KBr}$ discs) on the wavenumber range $4000-400 \mathrm{~cm}^{-1}$, with a JASCO-FT-IR-6600 spectrometer (Tokyo, Japan). X-ray diffraction (XRD) patterns were obtained in the range $2 \theta=10-80^{\circ}$, using a SmartLab X-Ray Diffractometer (RIGAKU, Tokyo, Japan), with $\mathrm{Cu} \mathrm{K}_{\alpha}$ radiation. TG/DTA had been carried out using a thermogravimetric and differential thermal analyzer (EXSTAR 6000 TG/DTA 6300N, Seiko Instruments Inc., Tokyo, Japan). The textural properties of the sorbent were acquired on a Quantachrome Nova 3200 surface area analyzer (Quantachrome Instruments, Boynton Beach, FL, USA) after degassing at room temperature for $3 \mathrm{~h}$. The specific surface area was determined by $\mathrm{N}_{2}$ adsorption/desorption isotherms, while the $\mathrm{BJH}$ method was used for evaluating porous volume. The material analysis and the morphology of sorbents were investigated with an ultra-high resolution FE-SEM SU8020 microscope equipped with an energy-dispersive X-ray spectrometer (SEM-EDX Hitachi, Tokyo, Japan) (without liquid $\mathrm{N}_{2}$ ). The samples were prepared by adhesion on a carbon film plate and they were sputter coated with a thin layer of platinum to impart conductivity for incident electrons. X-ray photoelectron spectroscopy was carried out using an X-ray photoelectron spectrometer (ESCA-5600, Japan) with $\mathrm{Mg} \mathrm{K} \mathrm{K}_{\alpha}\left(\mathrm{Al} \mathrm{K} \mathrm{K}_{\alpha}\right)$ radiation source ( $200 \mathrm{~W}$ power); the diameter of the $\mathrm{X}$-ray beam was $0.8 \mathrm{~mm}$, while the analysis diameter was $1 \mathrm{~mm}$. The samples were adhered on indium sheets. The $\mathrm{pH}_{\mathrm{PZC}}$ of the materials ( $\mathrm{pH}$ corresponding to the zero-charge at the surface of the sorbent particles) was determined by the $\mathrm{pH}$-drift method: the sorbents were equilibrated, under agitation for $24 \mathrm{~h}$, with a series of $0.1 \mathrm{M} \mathrm{NaCl}$ solutions controlled at different initial $\mathrm{pH}$ values $\left(\mathrm{pH}_{\mathrm{i}}\right)$. The equilibrium $\mathrm{pH}\left(\mathrm{pH}_{\mathrm{eq}}\right)$ was recorded. $\mathrm{The}_{\mathrm{pH}} \mathrm{PZC}_{\text {is }}$ the $\mathrm{pH}$ value corresponding to $\mathrm{pH}_{\mathrm{i}}=\mathrm{pH}_{\mathrm{eq}}[33,34]$.

\subsection{Metal sorption and desorption}

The study of sorption performance was carried out in batch reactor with investigation of $\mathrm{pH}$ effect, uptake kinetics, sorption isotherms, metal desorption and sorbent recycling. For the study of $\mathrm{pH}$ effect a volume of $25 \mathrm{~mL}$ of REE(III) solution was mixed with $10 \mathrm{mg}$ of sorbent; the mixture was agitated for $12 \mathrm{~h}$ at a velocity of $200 \mathrm{rpm}$, at room temperature (i.e., $26 \pm 1{ }^{\circ} \mathrm{C}$ ). The initial $\mathrm{pH}\left(\mathrm{pH}_{0}\right)$ was varied between 1 and 7 , while initial concentration was set to $75 \mathrm{mg} \mathrm{L}^{-1}$ (i.e., $0.548 \mathrm{mmol} \mathrm{La} \mathrm{L}^{-1}$ and $0.823 \mathrm{mmol} \mathrm{Y} \mathrm{L}^{-1}$ ). Sorption isotherms were obtained, at room temperature, at $\mathrm{pH}_{0} 5.0$; initial metal concentration varied from 25 to $400 \mathrm{mg} \mathrm{L}^{-1}$ (i.e., up to $2.9 \mathrm{mmol} \mathrm{La} \mathrm{L}^{-1}$ and $4.5 \mathrm{mmol} \mathrm{YL}^{-1}$ ). Kinetic measurements were performed by varying contact time for a sorbent dosage of $0.4 \mathrm{~g} \mathrm{~L}^{-1}$. After equilibration and phase separation by filtration, metal ion concentrations (before and after sorption) were determined by ICP-AES (Inductively Coupled Plasma Spectrometer, ICP SPS7800 SII, Seiko Instruments Inc., Tokyo, Japan). The sorption capacity ( $\mathrm{q}_{\mathrm{eq}}, \mathrm{mmol} \mathrm{g}^{-1}$ ) was calculated according to mass balance equation: $\mathrm{q}_{\mathrm{eq}}=\left(\mathrm{C}_{\mathrm{o}}-\mathrm{C}_{\mathrm{eq}}\right) \mathrm{V} / \mathrm{m}$, where $\mathrm{C}_{\mathrm{o}}$ and $\mathrm{C}_{\mathrm{eq}}$ (mmol metal $\mathrm{L}^{-1}$ ) are initial and equilibrium metal concentrations, respectively; $\mathrm{m}(\mathrm{g})$ is the weight of sorbent, and $\mathrm{V}(\mathrm{L})$ is the volume of 
solution. Experimental conditions are systematically reported in the captions of the figures: in most cases, the equilibrium time was $4 \mathrm{~h}$ and the experiments have been performed at room temperature (except specific information), and the $\mathrm{pH}$ was set at 5 . The issue on the comparison of sorption performances is illustrated by some examples reported in Additional Material Section (AMS, Section I).

Nitric acid $(0.5 \mathrm{M})$ was chosen as the eluent for the study of metal desorption. The contact time between the eluent and the metal-loaded sorbent was set to $1 \mathrm{~h}$ (under constant agitation). The adsorption-desorption experiments were executed for 5 cycles [35]; the desorption efficiency (DE) and the regeneration rate (RE) were calculated according:

$D E(\%)=\frac{C_{D} \times V \times 100}{q_{d} \times m_{d}}$

$R E(\%)=\frac{q_{d} \times 100}{q_{e}}$

where $\mathrm{C}_{\mathrm{D}}\left(\mathrm{mmol} \mathrm{L}^{-1}\right)$ is the metal ion concentration in desorption solution, $\mathrm{V}(\mathrm{L})$ is the volume of the desorption solution, $\mathrm{q}_{\mathrm{d}}\left(\mathrm{mmol} \mathrm{g}^{-1}\right)$ is the sorption capacity for metal-loaded material before desorption experiment, $\mathrm{q}_{\mathrm{e}}\left(\mathrm{mmol} \mathrm{g}^{-1}\right)$ is the sorption capacity at the first cycle, and $m_{d}(g)$ is the amount of the sorbent used in the desorption experiments.

Sorption tests were carried out on complex solutions obtained from alkaline leaching of monazite. The experimental procedure for the extraction of REEs from monazite ore is described in the Additional Material Section. The sorption test consisted of the contact at $25 \pm 1{ }^{\circ} \mathrm{C}$ of the REEs solution (at pH 3.92) with PPA-PGMA sorbent for $4 \mathrm{~h}$ (agitation $200 \mathrm{rpm}$ ). The $\mathrm{pH}$ control was performed using sodium carbonate/bicarbonate alkaline agent. The sorbent dosage was set to $0.4 \mathrm{gL}^{-1}$; this low SD allows achieving the saturation of the sorbent under selected experimental conditions (excess of metal ions).

\subsection{Sorption modeling}

Conventional equations were used for the modeling of uptake kinetics, including the pseudo-first order rate equation (PFORE), the pseudo-second order rate equation (PSORE), the simplified resistance to intraparticle diffusion equation (Weber and Morris equation applied on different segments of the kinetic profiles) and the Crank equation (for resistance to intraparticle diffusion). Relevant equations are reported in Additional Material Section (AMS, Section II).

For sorption isotherms the Langmuir, the Freundlich and the Sips equations were tested for fitting experimental curves. Relevant equations are summarized in Additional Material Section.

\subsection{Molecular modeling}

Theoretical modeling of the investigated phosphonate ligand and its metal complexes was performed using quantum chemical calculations. Geometry optimizations were carried out, using density functional theory Becke-3-parameter-Lee-Yang-Parr (DFT/B3LYP) [36-38], with the effective core potential (ECP/LANL2DZ) basis set [39]. Atomic charges were calculated using Mülliken approach. The distribution of the highest occupied and lowest unoccupied frontier molecular orbitals (HOMO/LUMO FMO) of the ligand and the complexes has been analyzed. ChemCraft program [40] was used for displaying computational results and plotting FMOs. Frequency calculations were conducted to ensure that the located structures are minima on their potential energy surfaces (no imaginary frequencies were recorded) and to correct zeropoint energy and thermal contributions. All electronic structure calculations were carried out using G03 program [41].

\section{Results and discussion}

\subsection{Synthesis of materials and characterization of sorbents}

Fig. 1 shows the schematic route for the synthesis of polyaminophosphonic acid-functionalized poly(glycidyl methacrylate) (PGMA) (i.e., PPA-PGMA). After synthesis of parent PGMA microparticles by dispersion polymerization method, diethylenetriamine is grafted on PGMA polymer (DETA-PGMA). In the last step of the process, methylene phosphonic groups are grafted on the intermediary product by reaction of phosphonic acid groups onto amine functions, in the presence of formaldehyde. The introduction of methylene phosphonic group onto chitosan macromolecule with phosphorous acid and formaldehyde may produce different types of derivatives. Indeed, the final product may bear both monophosphonic secondary amine (I) and tertiary diphosphonic amine (II) groups [16,42]:

Polymer - $\mathrm{NH}-\mathrm{CH}_{2}-\mathrm{PO}_{3} \mathrm{H}_{2}$

Polymer $-\mathrm{N}\left(-\mathrm{CH}_{2}-\mathrm{Po}_{3} \mathrm{H}_{2}\right)_{2}$

Several analytical techniques have been used to approach the identification of these reactive groups.

\subsubsection{Elemental analysis}

The chemical modification of PGMA can be followed comparing the elemental analysis of the product (CHN analysis) at the different stages of the synthesis (Table 1). Based on the theoretical structure of PGMA, the conversion of weight percentages for $\mathrm{C}, \mathrm{H}$ and $\mathrm{N}$ elements in molar units means that the polymer can be approached by the heptameric formula: $\left(\mathrm{C}_{7} \mathrm{H}_{10} \mathrm{O}_{3}\right)_{7}$. After reaction with DETA, nitrogen content reaches $12.46 \%\left(\mathrm{w} / \mathrm{w}\right.$ or $8.90 \mathrm{mmol} \mathrm{N} \mathrm{g}^{-1}$ ) due to the immobilization of the polyamine (diethylenetriamine, DETA). Comparing the theoretical fractions of nitrogen in DETA and in TA-PGMA, it is possible calculating the substitution degree close to $63 \%$.

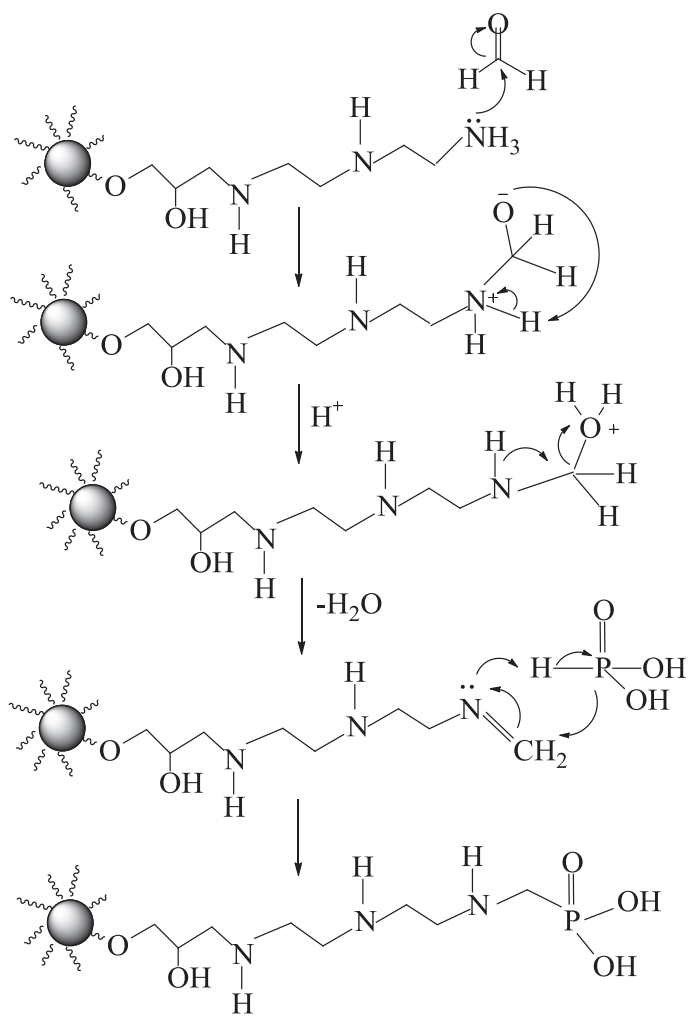

Fig. 1b. Revised process for the N-phosphonomethylation of TA-PGMA. 
Table 1

Elemental analysis of PGMA, Aminated-PGMA, PPA-PGMA.

\begin{tabular}{llllll}
\hline \multirow{2}{*}{ Material } & \multicolumn{5}{l}{ Elemental analysis (wt\%) } \\
\cline { 2 - 6 } & $\mathrm{C}$ & $\mathrm{H}$ & $\mathrm{N}$ & $\mathrm{P}$ & $\mathrm{O}^{*}$ \\
\hline PGMA & 57.8 & 7.26 & 0.31 & - & 34.63 \\
TA-PGMA & 42.85 & 7.69 & 12.46 & - & 37.00 \\
PPA-PGMA & 34.72 & 7.09 & 9.48 & 4.9 & 48.71 \\
\hline
\end{tabular}

* : obtained by difference to $100 \%$ (w/w fraction); n.d.: not determined.

The grafting of methylene phosphonic groups on the intermediary product (TA-PGMA) occurs by reaction of phosphonic acid groups onto amine functions in the presence of formaldehyde. The $P$ content (weight percentage) in the sorbent reaches $4.9 \%$ (i.e., $1.582 \mathrm{mmol} \mathrm{P} \mathrm{g}^{-1}$ ). The chemical grafting on chitosan backbone logically reduces the $\mathrm{C}$ and $\mathrm{N}$ mass fractions in the materials: the $\mathrm{N}$ content decreases from $12.46 \%$ to $9.48 \%(w / w)$ in the final PPA-PGMA. The simultaneous decreases of $C$ and $\mathrm{H}$ mass fractions are observed: $\mathrm{C}$ content drastically decreases from $42.85 \%$ to $34.72 \%(w / w)$, to a level comparable to C content in PGMA material. Assuming the mechanism of N-phosphonomethylation to follow the reaction described on Fig. 1, the amine groups can be grafted by either one phosphonomethyl moiety on secondary amine, or two phosphonomethyl moiety on primary amine. The grafting of 1 to 4 phosphonomethyl groups on TA-PGMA can be simulated, and the relevant weight fraction of $\mathrm{N}$ found in the product is $9.48 \%$. This is close to the calculated value (i.e., 9.77\%) for a derivative grafted with only one phosphonate moiety on the polymer backbone $\mathrm{H}_{2} \mathrm{PO}_{3}: \mathrm{R}-\mathrm{N}$ ratio: actually the simulated value would be $1.146 \mathrm{P}$ mole per mole of TAPGMA. The chemical analysis shows that the N/P molar ratio in PPAPGMA is close to 4.28. Obviously, despite the use of an excess of formaldehyde and phosphorous acid (to theoretically insure the complete substitution of all hydrogen atoms on primary and secondary amine groups), the substitution is not complete on amine groups. This may be explained by two reasons: (a) the poorest reactivity of secondary amine compared to primary amines [43]; this is reinforced by the fact that the reactivity on polymers is less than on monomer units, and (b) the hindrance effects limit the reactivity of the amine groups (decrease of the stability of the grafted polymer for polysubstituted structure). The $\mathrm{N}$-phosphonomethylation is efficient but leaves free a majority of amine groups: the sorbent is bi-functional associating amine and methylphosphonic reactive groups. On the basis of these observations it is possible to revise the final $\mathrm{N}$-phosphonomethylation, as shown on Fig. 1b.

\subsubsection{Sorbent morphology and semi-quantitative analysis: SEM and SEM-} EDX analysis

Scanning electron microscopy was used for characterizing the morphology of the materials (Fig. AM1, see AMS). PPA-PGMA particles can be described as irregular objects with irregular distribution in size (from approximately $40 \mu \mathrm{m}$ to $100 \mu \mathrm{m}$ ), and granular surfaces. The material does not show appreciable surface porosity. This is confirmed by BET analysis: the specific surface area (SSA) is close to $16 \mathrm{~m}^{2} \mathrm{~g}^{-1}$ (duplicate analysis). Despite several repetitions, the BET analysis did not allow getting an accurate evaluation of pore volume. This order of magnitude is consistent with reported values of SSA of PGMA: Wei et al. [44] cited a SSA close to $29 \mathrm{~m}^{2} \mathrm{~g}^{-1}$ for PGMA; the SSA increased with divinylbenzene co-polymer content.

Fig. 2 shows the EDX analysis of the samples (PGMA, PPA-PGMA, and PPA-PGMA after La and Y sorption): the grafting of amine groups is confirmed by the appearance of a small peak (poor sensibility) for $K_{\alpha} N$ signal (at $0.392 \mathrm{keV}$ ). On the other hand the N-phosphonomethylation is characterized by the appearance of the $\mathrm{K}_{\alpha} \mathrm{P}$ signal (at $2.01 \mathrm{keV}$ ). Figs. AM2 and AM3 (see AMS) compare the cartographies of element distribution at the surface of sorbent particles before and after metal sorption. The analyses show a great homogeneity of both the elements representative of reactive groups (i.e., $\mathrm{N}, \mathrm{P}$ and $\mathrm{O}$ ) and sorbed metals. It is noteworthy that the intensity of $\mathrm{N}$ element after metal sorption decreases (due to screening effect, or a decrease in its relative fraction, with poor detection sensibility). A semi-quantitative analysis (in triplicate) was also performed on metal-loaded sorbent (Fig. AM4, see AMS). Nitrogen content (after metal sorption) is close to $6.55 \pm 0.20 \%$ $(\mathrm{w} / \mathrm{w})$ much less than given by elemental analysis on PPA-PGMA (i.e., $12.46 \%, \mathrm{w} / \mathrm{w}$ ). This may be explained by the fraction of metal bound on the analyzed sample that decreases the relative fraction of $\mathrm{N}$ element in the total mass of material. Surprisingly, the semi-quantitative analysis of $\mathrm{P}$ shows a content close to $4.33 \pm 0.17 \%(\mathrm{w} / \mathrm{w})$; this is much closer than expected from the chemical analysis (i.e., 4.9\%,w/w). The mass fractions of $\mathrm{Y}$ and La are $5.05 \pm 0.31 \%(\mathrm{w} / \mathrm{w})$ and $9.55 \pm 0.85 \%(\mathrm{w} /$ $\mathrm{w}$ ), respectively; considering their respective atomic mass, their molar fractions are of the same order of magnitude (i.e., $0.57 \mathrm{mmol} \mathrm{Y} \mathrm{g}^{-1}$ and $0.69 \mathrm{mmol} \mathrm{La} \mathrm{g}^{-1}$ ). The EDX analysis of the samples after La and Y (III) sorption clearly shows the appearance of La and Y signals (Fig. 5) characterized by the peaks of $\mathrm{La}(\mathrm{III})$ at around $0.9,4.64$ and $5.05 \mathrm{keV}$, and the peaks of Y(III) at around 1.92 and $2.01 \mathrm{keV}$. The presence of Pt (and its "contaminants" as Rh and Ir) is due to the sputter coated layer deposited on the samples for EDX analysis.

\subsubsection{XRD analysis}

Fig. AM5 (see AMS) compares the X-ray diffraction patterns of PGMA and PPA-PGMA. PGMA is characterized by a poorly crystalline structure, marked by a shoulder at around $2 \theta=8^{\circ}$, a peak at $2 \theta=18^{\circ}$ and two other weak peaks or shoulders around $2 \theta=30^{\circ}$ and $38^{\circ}$ [45]. This XRD fingerprint, typical from PGMA materials, is strongly affected by the chemical modification (DETA grafting and subsequent phosphonomethylation). Indeed, the structure becomes more amorphous (smoothed and poorly resolved pattern) with quasi-disappearance of the peaks at $2 \theta=18^{\circ}$ and shoulders at $2 \theta=30^{\circ}$ and $38^{\circ}$. A new broad band appears, centered on $2 \theta=24^{\circ}$. Though the poorly resolved patterns do not allow calculating crystallinity indices, the chemical modification induces increased disorder of the structure of the polymer and the material becomes even more amorphous. This is consistent with previous studies that show that the chemical modification of biopolymer-based composites decreases the crystallinity of materials [19].

\subsubsection{Thermal properties}

The comparison of TGA and DTG profiles (thermogravimetric analysis and differential thermogravimetry) shows substantial differences in the degradation profiles (Fig. AM6, see AMS): the chemical modification of PGMA is confirmed. The TGA profile for PGMA shows several degradation steps:

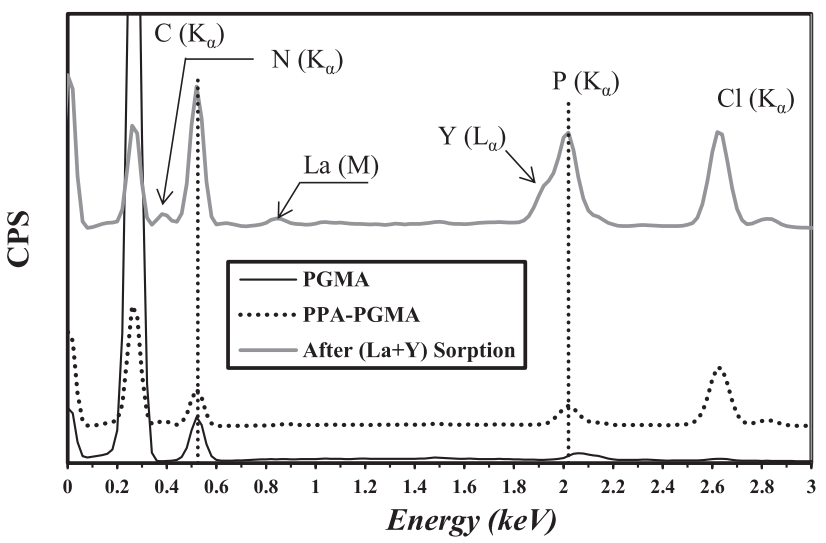

Fig. 2. EDX analysis of PGMA support, PPA-PGMA sorbent and La(III)/Y(III)loaded sorbent. 
(a) Stable plateau below $210^{\circ} \mathrm{C}$, with a weight loss limited to $2-3 \%$, which corresponds to the release of absorbed water.

(b) Sharp weight loss between $210^{\circ} \mathrm{C}$ and $344^{\circ} \mathrm{C}$ (with a maximum loss rate identified at $320^{\circ} \mathrm{C}$ on DTG curve); this is roughly consistent with conventional TGA thermogram of PGMA [46]: the maximum degradation rate was observed at $301{ }^{\circ} \mathrm{C}$. The degradation is attributed to random chain scission. The weight loss represents about $70 \%$.

(c) Between $344^{\circ} \mathrm{C}$ and $440{ }^{\circ} \mathrm{C}$ (maximum loss rate at $410{ }^{\circ} \mathrm{C}$ on DTG) PGMA loses $27 \%$ of its total weight; this corresponds to the degradation of shortened chains of the polymer with formation of a limited char (less than 3\%).

(d) Above $440{ }^{\circ} \mathrm{C}$ and up to $825^{\circ} \mathrm{C}$, PGMA is progressively losing the remaining char fraction for achieving complete degradation.

In the case of PPA-PGMA, the thermal degradation profile is more complex because of the presence of new organic chains that bear both amine and phosphonic groups:

(i) Between $25^{\circ} \mathrm{C}$ and $65^{\circ} \mathrm{C}$, the modified polymer, which is more hydrophilic, is releasing absorbed water (weight loss represents less than 14\%).

(ii) Stable plateau between $65^{\circ} \mathrm{C}$ and $230{ }^{\circ} \mathrm{C}$, with a little loss of weight (about $3 \%$ ), probably associated to the release of constitutive water (or more tightly bound to polymer chains).

(iii) In the range $230{ }^{\circ} \mathrm{C}-320^{\circ} \mathrm{C}$, a sharp decrease of weight is observed (about $38 \%$, with a maximum loss rate at $274{ }^{\circ} \mathrm{C}$ on DTG); this may be assigned to the degradation of the sorbent by polymer scission and/or to the degradation of amine chains.

(iv) Between $320^{\circ} \mathrm{C}$ and $430{ }^{\circ} \mathrm{C}$, a new weight loss is observed (corresponding to $21 \%$ of total mass), which is assigned to the degradation of phosphonate moieties and char formation.

(v) Above $430{ }^{\circ} \mathrm{C}$ and up to $925^{\circ} \mathrm{C}$, the char is progressively degraded, but even at $925^{\circ} \mathrm{C}$, the residual amount of solid represents $13 \%$ (w/w). Phosphorus-based compounds are frequently used as charforming additives for flame-retardant properties by improving char formation and partially preventing polymer scission [47].

The chemical modification improves water absorption, increases char formation, enhances thermal stability (lower slope of weight loss
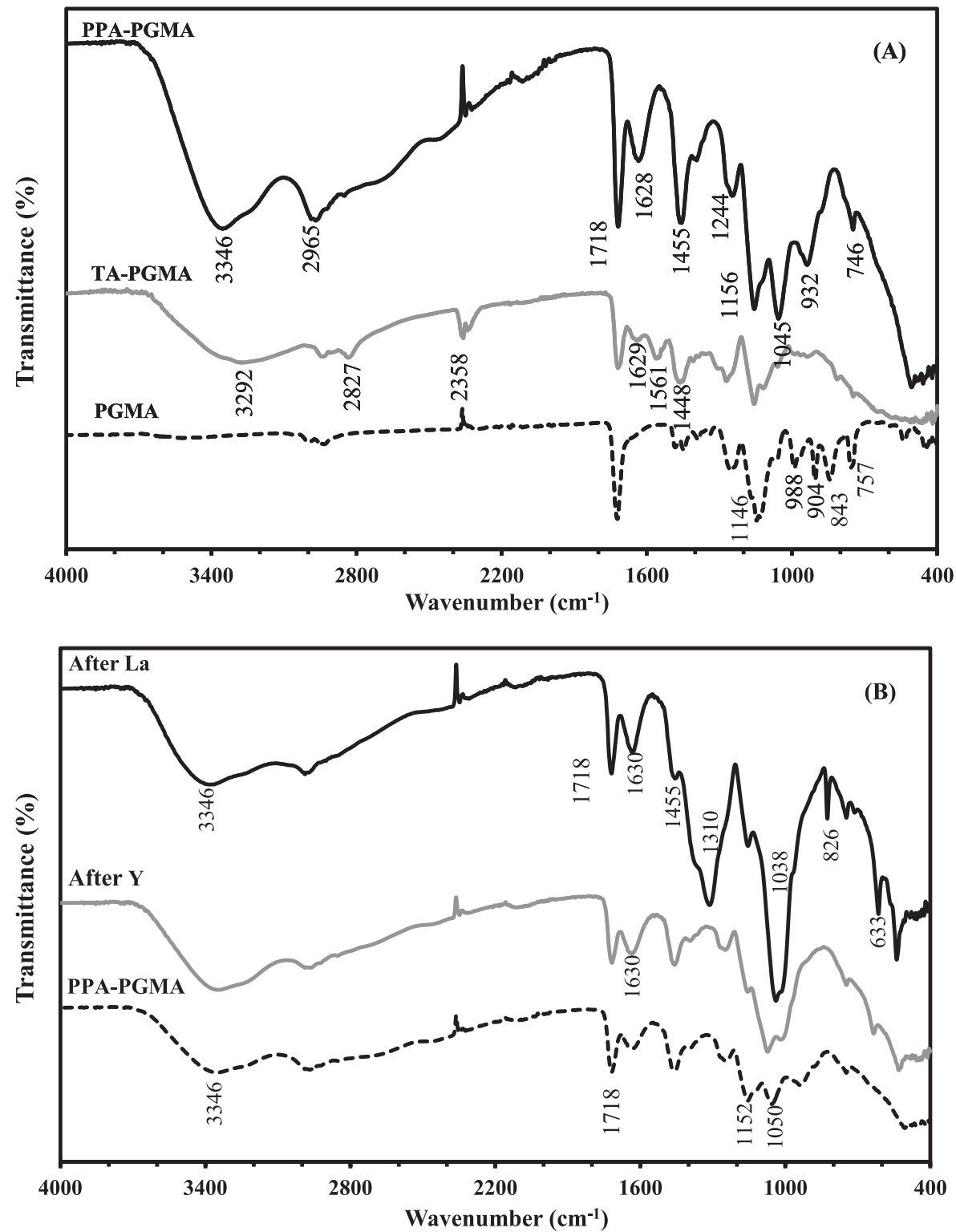

Fig. 3. FTIR spectra of PGMA, TA-PGMA and PPA-PGMA and spectra of PPA-PGMA before and after metal sorption (selected wavenumber ranges). 
and increased residual solid). I n addition, the degradation profiles shows that, compared to raw PGMA, the thermal degradation begins at lower temperature (shift of about $30^{\circ} \mathrm{C}$ ).

\subsubsection{FTIR analysis}

The successive chemical modifications of P GMA ( after grafting DETA and final grafting of phosphonomethyl groups) can be followed using FTI R spectrometry. FTI R spectrometry can also be used for identifying the functional groups that are involved in metal binding. These changes may be correlated to appearance, disappearance or shifts of characteristic bands [8,9]. Fig. 3 reports the evolution of FTIR spectra for the successive synthesized sorbents and also for metalloaded PPA-PGMA; spectra focused on selected wavenumber ranges are reported on Fig. AM7 (see AMS).

Based on the structure of PGMA the most significant groups that can be used for identifying the fingerprint of the polymer are: (a) the carbonyl groups ( $(-\mathrm{COO}-)$ ) ) at $1718 \mathrm{~cm}^{-1}[48]$, and (b) the oxirane ring characterized by asymmetrical expansion and stretching vibrations, at $843 \mathrm{~cm}^{-1}$ and $904 \mathrm{~cm}^{-1}$, respectively [13,49,50]. Another peak, close to $757 \mathrm{~cm}^{-1}$, has also been assigned to epoxy ring [51]. In the range $1300-1100 \mathrm{~cm}^{-1}$, the peaks have been assigned to $\mathrm{C}-\mathrm{O}$ stretching vibrations [51].

After DETA-grafting, the FTIR spectrum of TA-PGMA is characterized by the disappearance of the bands representative of epoxy ring
[52], while the peak at $1718 \mathrm{~cm}^{-1}$ remains visible: this means that the carbonyl groups are poorly affected by the chemical modification and that the grafting occurs by epoxy ring opening. On the other side, new bands appear at $1561 \mathrm{~cm}^{-1}$ and $1629 \mathrm{~cm}^{-1}$, attributable to $\mathrm{N}-\mathrm{H}$ bending modes in secondary and primary amines, respectively $[52,53]$. Similar modifications were observed in the case of cellulose modified first with PGMA and secondly by supplementary grafting of polyethyleneimine (PEI) [50], and on PGMA sorbent modified by grafting ethylene diamine [49]. Additional changes, poorly resolved, are observed around $3350 \mathrm{~cm}^{-1}$, due to the presence of $\mathrm{N}-\mathrm{H}$ groups (Fig. AM7, see AMS). The mode of grafting of amine compound on PGMA is also confirmed by the disappearance of the peaks associated to epoxy ring (i.e., at $904 \mathrm{~cm}^{-1}$, asymmetric vibration of epoxy ring) [52].

The final modification of TA-PGMA (occurring by reaction with phosphorous acid in the presence of formaldehyde) brings new P-based reactive groups. This is confirmed by the appearance of typical bands at $746 \mathrm{~cm}^{-1}$, assigned to $\mathrm{v}(-\mathrm{P}=\mathrm{O})$, at $932 \mathrm{~cm}^{-1}$, attributed to $\mathrm{P}-\mathrm{O}-\mathrm{C}$ stretching [53] or to $\mathrm{P}-\mathrm{OH}$ stretching [54], at $1045 \mathrm{~cm}^{-1}$, associated to $\mathrm{P}-\mathrm{O}-\mathrm{R}$ bond and at $1244 \mathrm{~cm}^{-1}$, assigned to $\mathrm{P}=\mathrm{O}$ bond [55]. These new peaks confirm the successful grafting of phosphorus-based reactive groups.

After La(III) and Y(III) binding, the intensity of the bands tends to decrease at $3357 \mathrm{~cm}^{-1}$ and $2966 \mathrm{~cm}^{-1}$, respectively. These changes can be directly associated to the binding of metal ions, which affects the
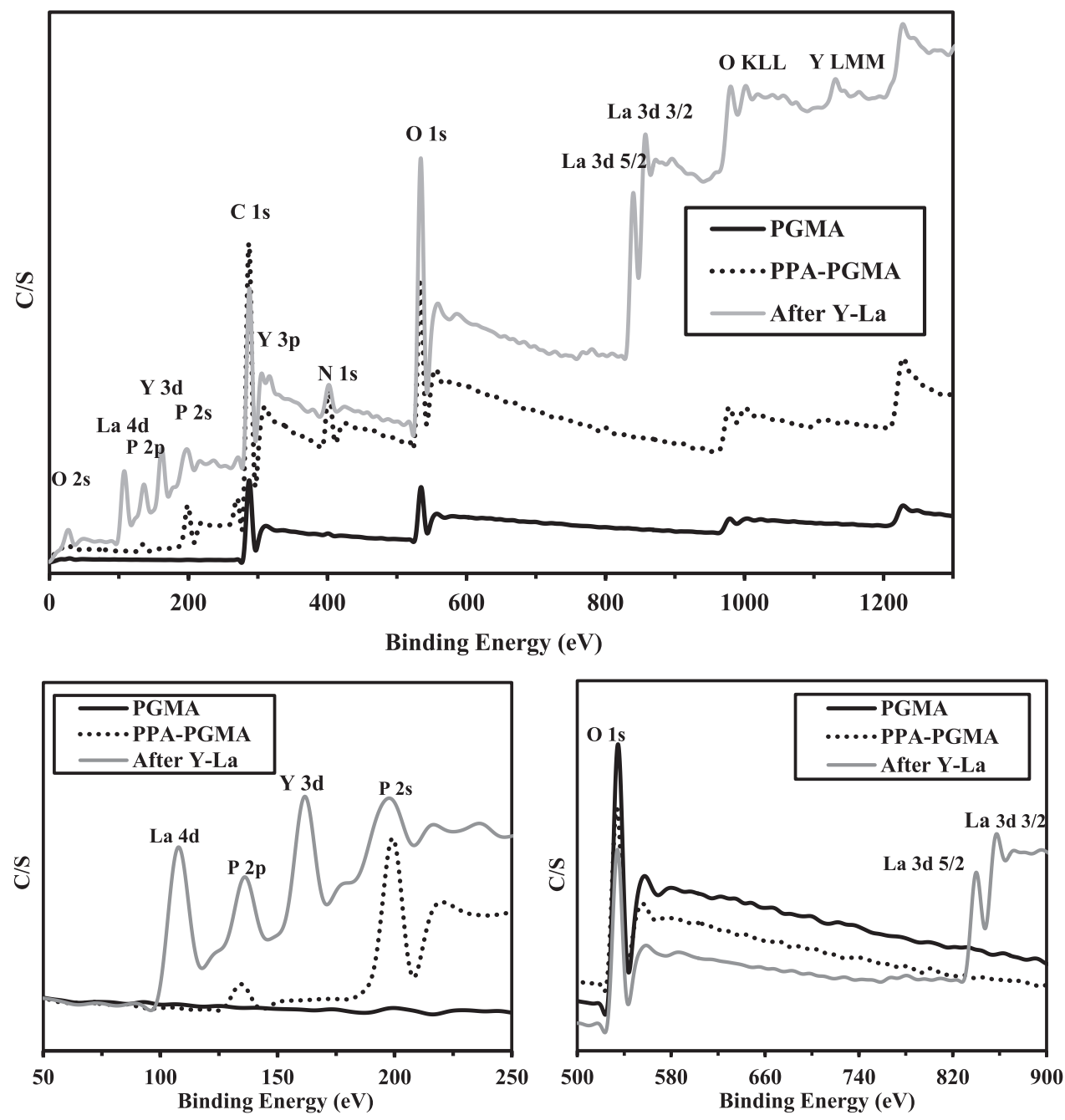

Fig. 4. XPS spectra of PGMA, PPA-PGMA, and PGMA after sorption of La(III) and Y(III). 
environment of $\mathrm{OH}$ and $\mathrm{NH}$ groups (superimposition of the relevant poorly resolved bands). In the case of Y(III)-loaded sorbent, the spectrum is similar to the sorbent spectrum: the main changes concern the blue shift of the band at $503 \mathrm{~cm}^{-1}$ (moved to $531 \mathrm{~cm}^{-1}$; this corresponds to $\mathrm{Y}-\mathrm{N}$ bond), the disappearance of the peak at $932 \mathrm{~cm}^{-1}$ ( $\mathrm{P}-\mathrm{O}-\mathrm{C}$ stretching), the shift of the peak at $1045 \mathrm{~cm}^{-1}$ (moved to $1074 \mathrm{~cm}^{-1}$, with appearance of a peak at $1018 \mathrm{~cm}^{-1}$ ), and the appearance of a new peak at $633 \mathrm{~cm}^{-1}$ (usually associated to the formation of $\mathrm{M}-\mathrm{O}$ bond) [53]. In the case of $\mathrm{Cu}(\mathrm{II})$ and $\mathrm{Mn}$ (II) binding to aminophosphonate-based ligands, Popa et al. [55] reported that the bands at $1050 \mathrm{~cm}^{-1}$ and $1250 \mathrm{~cm}^{-1}(\mathrm{P}=\mathrm{O}$ and $\mathrm{P}-\mathrm{O}-\mathrm{C}$ bonds) were also blue-shifted. Here, the band at $1250 \mathrm{~cm}^{-1}$ is not significantly affected by Y(III)sorption. The changes are much more marked in the case of La(III) sorption. The shift of the band at $506 \mathrm{~cm}^{-1}$ ( $\mathrm{La}-\mathrm{N}$ bond), the disappearance of the band at $932 \mathrm{~cm}^{-1}$ and the appearance of the $\mathrm{M}-\mathrm{O}$ bond at $633 \mathrm{~cm}^{-1}$, are also observed. However, a new peak is observed at $826 \mathrm{~cm}^{-1}$ (which is associated to $\mathrm{M}-\mathrm{CO}$ bond). A strong peak is observed at $1310 \mathrm{~cm}^{-1}$; this is usually a region where $\mathrm{C}-\mathrm{N}$ stretch vibration in amines is observed [53]; however, this could also correspond to the blue-shift of the $\mathrm{P}-\mathrm{O}-\mathrm{C}$ bond (appearing at $1250 \mathrm{~cm}^{-1}$ on the sorbent). In any case, the binding of La(III) strongly impacts the chemical environment of $\mathrm{N}$ - and $\mathrm{P}$ - reactive groups. The band observed at $1050 \mathrm{~cm}^{-1}(\mathrm{P}=\mathrm{O})$ is red-shifted to $1038 \mathrm{~cm}^{-1}$, with a strong increase in intensity after lanthanum binding. In the case of LDH (layered double hydroxide) intercalated biopolymer nanocomposites, the FTIR spectrum showed several bands in the range $400-800 \mathrm{~cm}^{-1}$ that correspond to $\mathrm{M}-\mathrm{OH}$ vibrations and $\mathrm{O}-\mathrm{M}-\mathrm{O}$ stretching [5].

\subsubsection{XPS analysis}

XPS spectroscopy is a useful and complementary tool for identifying the changes in the chemical composition of the polymer during the synthesis but also for improving the understanding of the chemical interactions between the sorbent and the metal ions. Fig. 4 shows that the chemical modification of PGMA introduces N-based reactive groups (due to DETA grafting on epoxy groups) and also P-based reactive groups (associated to phosphonomethylation of primary amino groups). After the contact with a binary $\mathrm{La}(\mathrm{III}) / \mathrm{Y}$ (III Iolution, the sorbent is characterized by the appearance of typical bands of La and Y elements.

The high resolution spectral bands of $\mathrm{C} 1 s, \mathrm{O} 1 s, \mathrm{~N} 1 s, \mathrm{P} 2 p, \mathrm{Y} 3 d$ and La $3 d$ bands are plotted on Fig. AM8 (see AMS). The figure allows identifying the different forms a ssociated to $\mathrm{P}, \mathrm{O}$ and $\mathrm{N}$ elements, in their different chemical environments. The proportions of the different chemical groups associated to $\mathrm{C}$ and $\mathrm{O}$ are poorly affected by the successive grafting of amine groups and phosphonate groups. The limited substitution of phosphonate on amine groups may explain the moderate impact on $\mathrm{O} 1 \mathrm{~s}$ signal: the only significant change is associated to a shift in BE of the peak at $534.7 \mathrm{eV}$ (shifted toward lower BE; i.e., $534.2 \mathrm{eV}$ ). The deconvolution analysis of $\mathrm{P} 2 p$ signal shows the appearance of poorly resolved peaks that allow identifying $\mathrm{P}-\mathrm{O}$, deprotonated, and protonated phosphonate groups. The coexistence of protonated and protonated amine groups (at similar atomic fractions) is also demonstrated by the presence of two deconvoluted peaks at $402.9 \mathrm{eV}$ and $400.8 \mathrm{eV}$, respectively. Chlorine element is present on PPA-PGMA (under two types and 4 deconvoluted peaks, probably associated to protonation of amine groups and residual traces of absorbed chloride anions) but almost disappears on the sorbent after metal sorption.

The interpretation of metal-related bands shows the co-existence of different $\mathrm{m}$ etal forms ( probable a ssociation $\mathrm{w}$ ith $\mathrm{C} 1, \mathrm{O} \mathrm{H}$ and $\mathrm{P}-\mathrm{O}^{-}$ groups). Indeed, La $3 d_{5 / 2}$ peaks appearing on Fig. AM8c show 2 couples of multiplet-splits at $836.2 / 839.9 \mathrm{eV}$, and $837.9 / 841.7 \mathrm{eV}$, respectively: the $\Delta \mathrm{E}$ is closed to $3.7 \mathrm{eV}$ (values of $3.9 \mathrm{eV}$ and $3.5 \mathrm{eV}$ were reported for $\mathrm{La}(\mathrm{OH})_{3}$ and $\mathrm{La}_{2}\left(\mathrm{CO}_{3}\right)_{3}$, respectively). The changes observed on $\mathrm{O} 1 \mathrm{~s}$ and $\mathrm{P} 2 p$ signals (see below) suggest that one of these forms is associated to phosphonate-La(III)interaction, while the other may be associated to chloride. The $\mathrm{pH}$ was controlled with $\mathrm{HCl}$, which was also used for preparing stock solutions. However, the atomic fraction of chloride being very low, other species may co-exist. Other possibilities may consist of interactions with amine groups: the BEs are not changed but the fraction of free amine groups increases after metal sorption, or to hydroxo or hydroxo-chloride complexes. In the case of Y $3 d$ signals, 6 peaks can be identified on the deconvolution of the spectra: 3 pairs ( $Y$ $3 d_{3 / 2}$ and Y $3 d_{5 / 2}$ bands) appear, associated to chloride species (at the highest binding energies), and phosphonate species. It is noteworthy that the sorption of metal ions induces a shift toward lower BEs (higher electronic density) for $\mathrm{P}-\mathrm{O}$ peaks (with lower relative intensity), a relative stability of BEs for phosphonate groups, and the simultaneous decrease of the intensity of deprotonated phosphonate and increase of the intensity of protonated phosphonate. The chemical environment of $\mathrm{O}$ element is mainly affected by metal sorption for $\mathrm{P}-\mathrm{O}$ group: the $\mathrm{BE}$ is shifted from $531.8 \mathrm{eV}$ to $530.8 \mathrm{eV}$ (with simultaneous decrease in intensity). Other signals are not shifted in terms of BEs, but the relative intensities of $\mathrm{O}$ strongly change (increase for $\mathrm{C}-\mathrm{O}-\mathrm{C}$ and decrease for $\mathrm{C}-\mathrm{OH}$ and $\mathrm{P}-\mathrm{OH})$.

These results are consistent with FTIR analysis and demonstrate the contribution of phosphonate groups in metal binding with co-existence of different complexes, or different interactions with the neighboring reactive groups.

\subsubsection{Molecular modeling of metal interactions with PPA-PGMA}

A detailed discussion of DFT calculations is presented in the Additional Material Section (Section III). It is noteworthy that the simulation was performed on isolated free ligand; obviously, the immobilization of the ligand at the surface of the polymer matrix introduces additional and important constraints. However, this allows a first approach of the binding mechanisms.

Taking into account the increased sorption of target metals with increasing the $\mathrm{pH}$, it is assumed, for the modeling approach, that metal binding occurs after deprotonation of aminophosphonic acid groups. Selection of the optimal energetically efficient structures is based on attractive and repulsive forces that result in a more favorable orientation of the interacting system. Comparison of binding energies, bond lengths (between metal and reactive atoms on the sorbent or in water), Mülliken charges (for relevant reactive atoms), HOMO and LUMO surfaces, and energy gaps help in understanding experimental findings.

Fig. 5 shows the structures suggested by DFT modeling for the interaction between the methyl-aminophosphonic ligand and La(III) and $\mathrm{Y}(\mathrm{III})$ metal ions. The metal ions coordinate to the ligand through tetradentate mode. The metal ion binding to the ligand occurs through:

(a) One bond with one deprotonated oxygen atom from phosphonate group (via ionic bond),

(b) Two bonds with nitrogen donors (amine groups, via coordinate bond),

(c) One bond with one oxygen donor from OH groups (via coordinate bond).

In order to complete their coordination sphere, the metal ions are also bound to two chloride ions, and one oxygen donor atom from water molecules (hydration). This is consistent with the EDX analysis of sorbents after metal loading: a substantial amount of chlorine is identified. On the other hand, XPS analysis does not allow clearly identifying the interaction of amine groups to metal binding: small changes to relative intensity of the bands with limited shifting in binding energies are observed. Oxygen donors of phosphonate groups are binding metal ions more strongly than nitrogen donors of amine groups, as a consequence of short $\mathrm{M}-\mathrm{O}$ bond lengths and higher negative charge on the oxygen atoms.

\subsection{8. $p H_{P Z C}$}

The $\mathrm{pH}$-drift method was used for the determination of the $\mathrm{pH}_{\mathrm{PZC}}$ of PGMA, TA-PGMA, and PPA-PGMA (Fig. AM8, see AMS). The successive chemical modifications strongly influence the acid-based properties of 
PGMA derivatives. As expected, grafting DETA on the polymer (TAPGMA) brings basic groups (i.e., amine groups) on the polymer: the $\mathrm{pH}_{\mathrm{PZC}}$ increases from 5.9 to 8.43 . This is directly correlated to the $\mathrm{pK}_{\mathrm{a}}$ values of amine groups in DETA (i.e., 3.58, 8.86 and 9.65) [56]. In the case of wheat residue modified by grafting of DETA, Chen et al. (2010) reported $\mathrm{pH}_{\mathrm{PZC}}$ value close to 5: this means much lower than the level obtained with TA-PGMA. Closer $\mathrm{pH}_{\mathrm{PZC}}$ value (i.e., 8.2) was reported for DETA-functionalized graphene oxide [57].

However, after phosphonomethylation, the trend is completely reversed and the $\mathrm{pH}_{\mathrm{PzC}}$ decreases to 2.69 . The $\mathrm{pK}_{\mathrm{a}}$ value of methylphosphonate moiety is closed to 2.35 . In the case of chitosan functionalization with methyl and phenyl aminophosphonate moieties, Imam et al. [19] reported diverging trends for the value of $\mathrm{pH}_{\mathrm{PzC}}$ : phenyl-derivative drives the $\mathrm{pH}_{\mathrm{PZC}}$ to 3.13 while methyl-derivative raises its value to 6.24. The strong displacement of $\mathrm{pH}_{\mathrm{PZC}}$ after phosphonomethylation suggests that the most alkaline amine groups have disappeared and that the level of substitution is quantitative. The analysis of acid-base properties of $\alpha$ aminophosphonic acids showed that the stronger acid group has a $\mathrm{pK}_{\mathrm{a} 1}$ value in the range $0.5-1.5$ (associated to $-O$ group; i.e., stronger than the acidity of carboxylic groups, which is close to 2.2-3) while the second $\mathrm{pKa}_{2}$ is much higher (i.e., in the range 5-6) [58]. Aminophosphonic acids have a zwitterion effect due to the internal hydrogen transfer between $\mathrm{P}-\mathrm{OH}$ and amino groups [58]. The electron attractive forces of $\mathrm{P}=\mathrm{O}$ group reduces the electron density around the amino group, which, in turn, decreases their $\mathrm{pK}_{\mathrm{a}}$ values. In the case of ES 467 ion-exchange resin (which bears aminomethylphosphonic acid moieties), Sahni et al. [59] reported the mechanisms of dissociation of the different reactive groups: at $\mathrm{pH} 1$, the a mino group is protonated and one of the $\mathrm{P}-\mathrm{OH}$ groups is deprotonated (zwitterion: $\mathrm{R}-\odot$ $\mathrm{CH}_{2}-\mathrm{N}^{+} \mathrm{H}_{2}-\mathrm{CH}_{2}-\mathrm{P}=\mathrm{O}(\mathrm{OH})\left(\mathrm{O}^{-}\right)$), while at $\mathrm{pH}$ close to 6 , the hydroxyl groups on the phosphonate group are completely deprotonated $\left(\mathrm{R}-\mathrm{CH}_{2}-\mathrm{N}^{+} \mathrm{H}_{2}-\mathrm{CH}_{2}-\mathrm{P}=\mathrm{O}\left(\mathrm{O}^{-}\right)_{2}\right)$. While raising the $\mathrm{pH}$ to 11 , amine group is deprotonated, while all the hydroxyl groups are deprotonated (anionic aminophosphonate compound: $\mathrm{R}-\mathrm{CH}_{2}-\mathrm{NH}_{2}-\mathrm{CH}_{2}-\mathrm{P}=\mathrm{O}$ $\left.\left(\mathrm{O}^{-}\right)_{2}\right)$. This is roughly consistent with the titration profile observed for PPA-PGMA on Fig. AM9 (see AMS) [19]. This acid-base behavior helps in predicting the electrostatic attraction/repulsion of the sorbent for charged metal ions (pure electrostatic effects) and for the competition

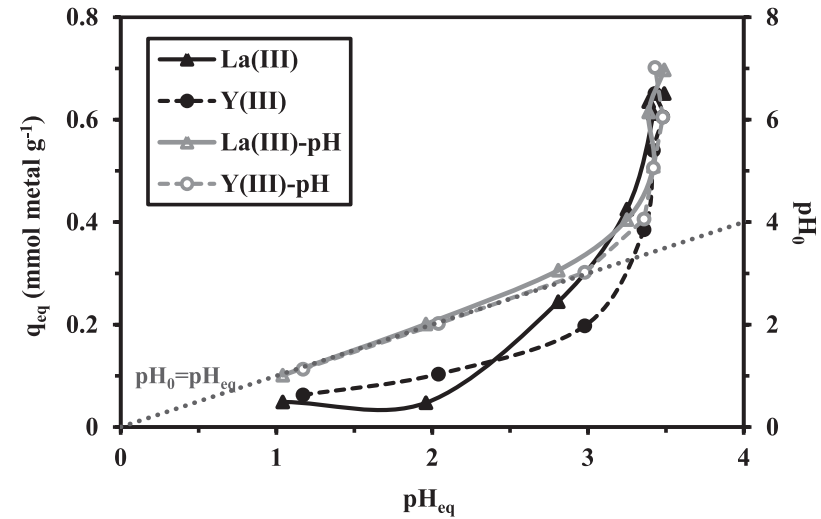

Fig. 6. Effect of $\mathrm{pH}_{\mathrm{eq}}$ on sorption capacity (and comparison of $\mathrm{pH}_{0}$ and $\mathrm{pH}_{\mathrm{eq}}$ ) $\left(\mathrm{C}_{\mathrm{o}}\right.$ : $75 \mathrm{mg}$ metal L$^{-1} \quad\left(0.548 \mathrm{mmol} \mathrm{La} \mathrm{L}^{-1}\right.$ and $\left.0.823 \mathrm{mmol} \mathrm{Y} \mathrm{L}^{-1}\right)$; Temperature, T: $26^{\circ} \mathrm{C}$; Sorbent dosage, SD: $0.4 \mathrm{~g} \mathrm{~L}^{-1}$; Contact time, time: $12 \mathrm{~h}$ ).

of protons (chelation and ion-exchange properties). Obviously, other parameters associated to metal speciation may affect the affinity of the sorbent for metal ions, in addition to the protonation/deprotonation of reactive groups on the material.

\subsection{Sorption studies}

\subsubsection{Effect of $\mathrm{pH}$ and interpretation of sorption mechanisms}

The $\mathrm{pH}$ is expected to influence both (a) the speciation of metal ions, by formation of hydrolyzed species (including unfavorable precipitation), or specific complexes in the presence of ligands, and (b) the surface properties of the sorbents, by protonation and deprotonation of reactive groups $[13,16]$. The presences of phosphonic acid and amine groups induce various proton exchange reactions; however, their affinity for metal ions is modulated by the $\mathrm{pH}$ of the solution $[13,16,18]$. Fig. 6 and Fig. AM10 (see AMS) show the effect of equilibrium pH on the sorption of $\mathrm{La}(\mathrm{III})$ and $\mathrm{Y}(\mathrm{III})$ (sorption capacity and $\mathrm{pH}$ variation, and sorption efficiency, respectively).

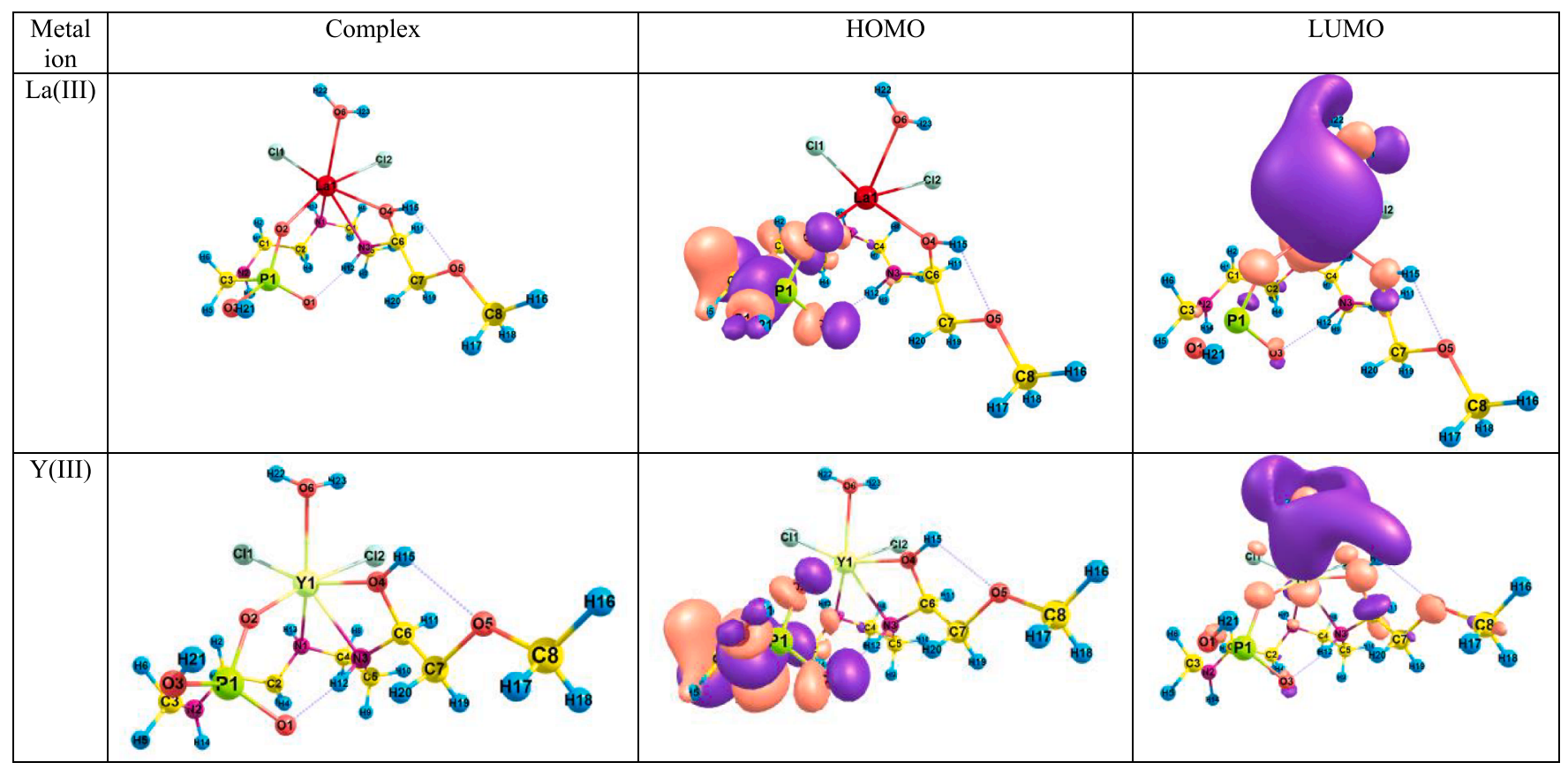

Fig. 5. Tentative structures of complexes between Y(III) or La(III) and aminophosphonate ligand. 
Under selected experimental conditions, at low pH (below 3), the protonation of all reactive groups induces a strong repulsion effect: the competition of protons limits the sorption of cationic metal species. Fig. AM11 (see AMS) shows the speciation diagram of La(III)and Y(III), under the conditions corresponding to $\mathrm{pH}$ studies ( $\mathrm{HCl}$ acid used for $\mathrm{pH}$ control, etc.): REEs are only present as cationic species. Free REEs are largely predominating: $\mathrm{REE}-\mathrm{Cl}_{2}{ }^{+}$species represent less than $20 \%$ of total metal concentration, and their concentration becomes negligible when the $\mathrm{pH}$ rises to 2-3. On this $\mathrm{pH}$ range, the equilibrium $\mathrm{pH}$ does not significantly changes during metal sorption; this is consistent with the titration curve obtained for the determination of $\mathrm{pH}_{\mathrm{PZC}}$ (Fig. AM9, See AMS): the sorbent has a kind of buffering effect between $\mathrm{pH} 1$ and 2.69 with a negligible $\Delta \mathrm{pH}$. At $\mathrm{pH}$ above 3 , the sorption capacity of both La (III) and Y(III) sharply increases: the profiles of the two metal ions are very close; this means that simply playing with the $\mathrm{pH}$ will not allow separating these two metal ions. With a $\mathrm{pH}_{\mathrm{PZC}}$ close to 2.69 , the sorbent progressively deprotonates above $\mathrm{pH} 3$ : the repulsive effect of protonated surface (protonated amine groups) decreases and the phosphonic groups bear increasing fraction of $\mathrm{P}^{-} \mathrm{O}^{-}$groups; both contribute to increase sorption efficiency. The $\mathrm{pH}$ of the so lution sh arply decreases (Fig. 6): for $\mathrm{pH}_{0}$ values in the range 4-7, the equilibrium $\mathrm{pH}$ varies between $\mathrm{pH} 3.2$ and 3.4; protons are released and replaced with $\mathrm{La}(\mathrm{III})$ and Y(III). The sorption mechanisms involve ion-exchange of protons with metal cations on $-\mathrm{PO}^{-}$reactive groups. In addition, the deprotonation of reactive groups enhances metal complexation on phosphonate and free amine groups. This is again consistent with the titration curve (Fig. AM8, see AMS). Maximum sorption capacities are obtained for solutions with initial $\mathrm{pH}$ controlled to 5-6 (but with equilibrium $\mathrm{pH}$ close to 3.4): the two metal ions have approximately the same sorption capacity close to $0.65 \mathrm{mmolg}^{-1}$. Fig. AM12 (see AMS) shows the logplot of the distribution coefficient $\left(\mathrm{K}_{\mathrm{d}}=\mathrm{q}_{\mathrm{eq}} / \mathrm{C}_{\mathrm{eq}}\right)$ vs. $\mathrm{pH}_{\mathrm{eq}}$. The profiles for both La(III) and Y(III) are characterized by two segments. The slopes of the segments the most useful (i.e.; at $\mathrm{pH}$ above 3 ) are close to 0.92 for $\mathrm{La}(\mathrm{III})$ and 1.25 for Y (III). This kind of plot is useful in ion-exchange processes for identifying the stoichiometric ratio for the exchange between protons and metal ions. This means that one proton could be released from the aminophosphonate moiety (or protonated amine groups) and exchanged with one REE ion. Actually, the binding process is probably driven by the deprotonation of reactive groups with $\mathrm{pH}$ increase; and this deprotonation favors the chelation of target metals with amine and phosphonic groups on PPA-PGMA. The effective binding process probably involves ion-exchange and chelating mechanisms, with relative contributions that depend on the $\mathrm{pH}$ of the solution.

The $\mathrm{pH}$ was not increased above 7 to prevent metal precipitation and/or formation of REE hydroxo colloids, which may reduce the sorption efficiency $[5,6,60]$, in ad dition to lo cal pr ecipitation phenomena.

\subsubsection{Uptake kinetics}

Fig. 7 shows the kinetic profiles for the sorption of La(III) and Y(III) on PPA-PGMA. The first step in the process, within $60 \mathrm{~min}$ of contact, corresponds to $70-80 \%$ of total metal sorption, while the equilibrium is reached within 180-240 min. The first step corresponds to the sorption at the surface of sorbent particles (with possible contribution of sorbent swelling phenomena), while the second step (more slowly) accounts for the sorption of metal ions in the core of the particles (though intraparticle diffusion) [61-63]. R esistance to intraparticle diffusion is usually an important limiting step in the control of uptake kinetics (in addition to resistance to film diffusion, predominant du ring the first minutes of contact, bulk diffusion, and the proper reaction rate). Using small particle sizes obviously limits the effect of $\mathrm{r}$ esistance $\mathrm{t} o$ intraparticle diffusion; this effect can be even minored when the sorbent is highly porous (high specific surface area, pore size, pore volume, etc) [64-66]. The textural properties (analyzed by BET method) showed that the specific surface area was relatively small (i.e., $16 \mathrm{~m}^{2} \mathrm{~g}^{-1}$ ). The sorbent is poorly porous; the small size of sorbent particles allows achieving a relatively fast uptake: the slow diffusion to access internal reactive groups represents a limited fraction of total sorption. This poor porosity may induce resistance to intraparticle diffusion.

The PFORE, PSORE, RIDE (Crank equation) have been used to simulate the kinetic profiles (Fig. 7); the parameters of the models were determined by non-linear regression. The sRIDE equation (multi-segment Weber and Morris equation) was also used or identifying different modes of resistance to intraparticle diffusion (associated to different porous characteristics or steps in the diffusion process: film diffusion, diffusion into porous network of different pore sizes) (Fig. AM13, see AMS). Within the first $30 \mathrm{~min}$ of contact, the steep linear section corresponds to the sorption controlled by film diffusion and sorbent swelling, the second section (with a lower slope) lasts for $3 \mathrm{~h}$ and
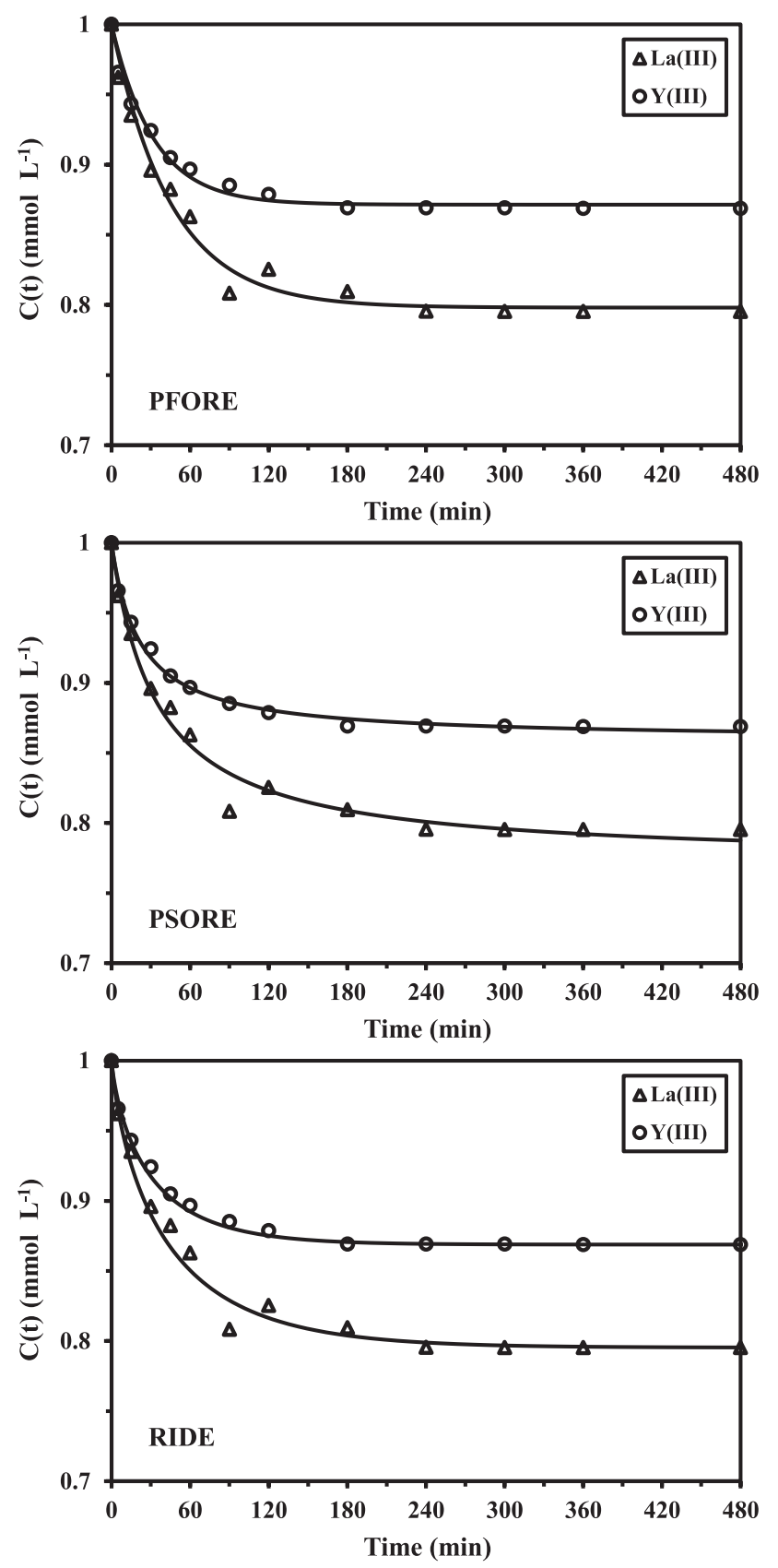

Fig. 7. La(III) and Y(III) uptake kinetics using PPA-PGMA - Modeling with the PFORE, the PSORE and the RIDE (Crank) equations (pH: 5.01; $\mathrm{C}_{\mathrm{o}}: 200 \mathrm{mg} \mathrm{L}^{-1}$; T: $26^{\circ} \mathrm{C}$; SD: $0.4 \mathrm{~g} \mathrm{~L}^{-1}$ ). 
Table 2

Uptake kinetics for La(III) and Y(III) sorption using PPA-PGMA - Parameters of the models.

\begin{tabular}{|c|c|c|c|c|}
\hline \multirow[t]{2}{*}{ Metal } & \multirow[t]{2}{*}{$\mathrm{q}_{\mathrm{eq}, \exp }\left(\mathrm{mmol} \mathrm{g} \mathrm{g}^{-1}\right)$} & \multicolumn{3}{|c|}{ PFORE } \\
\hline & & $\mathrm{q}_{\mathrm{eq}, 1}\left(\mathrm{mmol} \mathrm{g}^{-1}\right)$ & $\mathrm{k}_{1} \times 10^{2}\left(\min ^{-1}\right)$ & $\mathrm{R}^{2}$ \\
\hline $\mathrm{La}(\mathrm{III})$ & 0.791 & 0.780 & 2.21 & 0.983 \\
\hline $\mathrm{Y}(\mathrm{III})$ & 0.742 & 0.727 & 3.12 & 0.985 \\
\hline
\end{tabular}

PSORE

\begin{tabular}{|c|c|c|c|c|}
\hline & & $\mathrm{q}_{\mathrm{eq}, 2}\left(\mathrm{mmol} \mathrm{g}^{-1}\right)$ & $\mathrm{k}_{2} \times 10^{2}\left(\min ^{-1}\right)$ & $\mathrm{R}^{2}$ \\
\hline La(III) & 0.791 & 0.880 & 3.29 & 0.951 \\
\hline Y(III) & 0.742 & 0.795 & 5.85 & 0.920 \\
\hline
\end{tabular}

\begin{tabular}{|c|c|c|c|}
\hline & \multicolumn{3}{|c|}{ RIDE - Crank equation } \\
\hline & $\mathrm{D}_{\mathrm{e}} \times 10^{11}\left(\mathrm{~m}^{2} \min ^{-1}\right)$ & & $\mathrm{R}^{2}$ \\
\hline La(III) & 1.39 & & 0.986 \\
\hline \multirow[t]{3}{*}{ Y(III) } & 2.07 & & 0.996 \\
\hline & \multicolumn{3}{|c|}{ sRIDE } \\
\hline & $\mathrm{k}_{\mathrm{id}, 1}\left(\mathrm{mmol} \mathrm{g}^{-1} \min ^{-0.5}\right)$ & $\mathrm{k}_{\mathrm{id}, 2}\left(\mathrm{mmolg}^{-1} \min ^{-0.5}\right)$ & $\mathrm{k}_{\mathrm{id}, 3}\left(\mathrm{mmol} \mathrm{g}^{-1} \min ^{-0.5}\right)$ \\
\hline $\mathrm{La}(\mathrm{III})$ & 0.0722 & 0.0416 & 0.0001 \\
\hline $\mathrm{Y}(\mathrm{III})$ & 0.0784 & 0.0298 & 0.0003 \\
\hline
\end{tabular}

Experimental conditions: $\mathrm{pH}: 5.01 ; \mathrm{C}_{\mathrm{o}}: 200 \mathrm{mg} \mathrm{L}^{-1}$; $\mathrm{T}: 26^{\circ} \mathrm{C}$; SD: $0.4 \mathrm{~g} / \mathrm{L}$.

corresponds to the control of mass transfer by resistance to intraparticle diffusion. Above $3 \mathrm{~h}$, a very weak sorption is observed corresponding to the diffusion of metal species through the porous network of smaller pore size.

Table 2 summarizes the parameters of the different models, and the relevant correlation coefficients. The best correlation was obtained using the RIDE: the determination coefficients are close or higher than 0.99. On the other hand, the PFORE shows higher determination coefficients than the PSORE; in addition, the values of $\mathrm{q}_{\mathrm{eq}, 1}$ are closer (under estimated) to experimental values ( $\mathrm{q}_{\mathrm{eq}, \mathrm{exp}}$ ) than $\mathrm{q}_{\mathrm{eq}, 2}$ (much over estimated). The PFORE is thus the most appropriate reaction rate equation for fitting experimental profiles. Yttrium sorption is little faster than lanthanum uptake: the equilibrium is reached after $180 \mathrm{~min}$ for $\mathrm{Y}(\mathrm{III})$ compared to $\mathrm{La}(\mathrm{III})$, where a contact time of $240 \mathrm{~min}$ is necessary for reaching equilibrium. The hydrated radius of $\left.\mathrm{Y}_{(2} \mathrm{H}_{2} \mathrm{O}\right)_{8}{ }^{3+}$ (square antiprism structure) is close to $1.019 \AA$ while $\mathrm{La}\left(\mathrm{H}_{2} \mathrm{O}\right)_{9}{ }^{3+}$ (tricapped trigonal prism structure) has a larger hydrated radius (close to $1.216 \AA$ ) [67].

The fit of experimental profiles using the Crank equation allows determining the effective diffusivity coefficient $\left(D_{e}\right)$ in the sorbent for La(III) and Y(III): $1.39 \times 10^{-11} \mathrm{~m}^{2} \mathrm{~min}^{-1}$ and $2.07 \times 10^{-11} \mathrm{~m}^{2} \mathrm{~min}^{-1}$, respectively. These values are about 3 orders of magnitude lower than the self-diffusivity of La(III) and Y(III) in water: $3.71 \times 10^{-8} \mathrm{~m}^{2} \mathrm{~min}^{-1}$ and $3.30 \times 10^{-8} \mathrm{~m}^{2} \mathrm{~min}^{-1}$, respectively [68]. This strong difference confirms that the resistance to intraparticle diffusion plays an important role in the control of mass transfer.

As a conclusion, the sorption is controlled within the first $30 \mathrm{~min}$ of contact by the combination of resistance to film diffusion and sorbent swelling, while the resistance to intraparticle diffusion plays a major role in the second phase of the mass transfer. The reaction rate is best fitted by the pseudo-first order reaction equation.

\subsubsection{Sorption isotherms and thermodynamics}

The sorption isotherms represent the distribution of the solute between the liquid and the solid phases at equilibrium, for different solute concentrations, at fixed temperature [69]. Fig. 8 shows the sorption isotherms for $\mathrm{La}(\mathrm{III})$ and $\mathrm{Y}(\mathrm{III})$, at $\mathrm{pH}_{0} 5$ and $26^{\circ} \mathrm{C}$, while Table 3 reports the relevant parameters of the models used for fitting experimental profiles. The profiles exhibit the characteristic shape of
Langmuir isotherms with a saturation plateau; this means that the Freundlich equation (which is a power-like function) is not appropriate for modeling this kind of profile (confirmed by the low values of determination coefficients). Fig. AM14 (see AMS) shows the comparison of the fits for the different models. Usually, introducing a third fitting parameter, as in the Sips equation, improves the quality of the mathematical simulation of experimental sorption isotherms; this is not the case here. Table 3 also compares the modeling of experimental data using the Langmuir equation with both the linear and the non-linear methods. Unexpectedly, the linear regression analysis allowed a little better fit of sorption isotherms (considering the calculated value of the maximum sorption capacity; i.e., sorption capacity at saturation of monolayer). The deviation of the $\mathrm{q}_{\max }$, between calculated and experimental values, ranges between $3 \%$ and $6 \%$.

The maximum sorption capacities are of the same order of magnitude: $0.793 \mathrm{mmol} \mathrm{La} \mathrm{g}^{-1}$ and $0.774 \mathrm{mmol} \mathrm{Y} \mathrm{g}^{-1}$. The initial slope of the curve, which is correlated to the affinity of the sorbent for target metal, is little higher for $\mathrm{La}(\mathrm{III})$ than for $\mathrm{Y}(\mathrm{III})$ : the $\mathrm{b}$ coefficient is close to $13 \mathrm{~L} \mathrm{mmol}^{-1}$ for La(III) vs. $5.15 \mathrm{~L} \mathrm{mmol}^{-1}$ for $\mathrm{Y}$ (III). The experimental

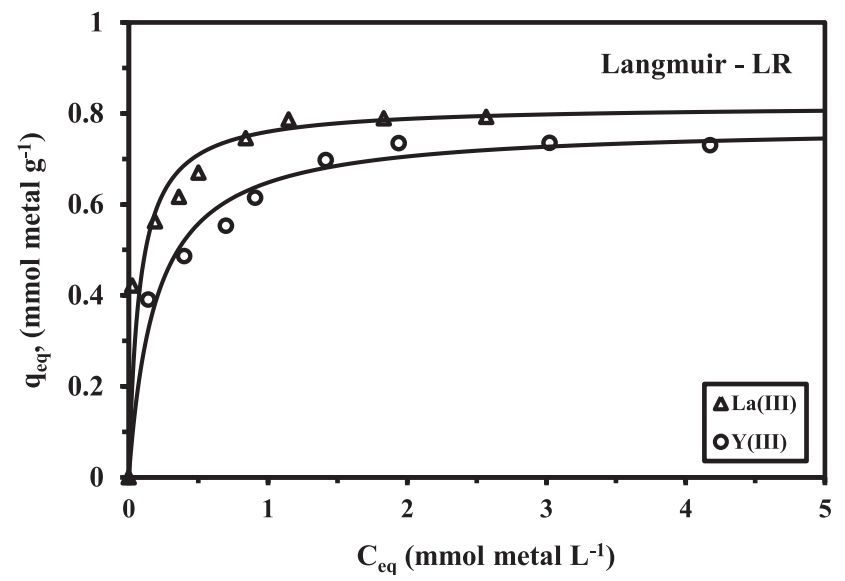

Fig. 8. La(III) and Y(III) sorption isotherms using PPA-PGMA - Modeling with the Langmuir equation (pH: 5.10; T: $26^{\circ} \mathrm{C}$; SD: $0.4 \mathrm{~g} \mathrm{~L}^{-1}$; time: $4 \mathrm{~h}$ ). 
Table 3

La(III) and Y(III) sorption isotherms - Parameters of the models.

\begin{tabular}{llll}
\hline Model & Parameter & La(III) & Y(III) \\
\hline Experimental & $\mathrm{q}_{\max }\left(\mathrm{mmol} \mathrm{g}^{-1}\right)$ & 0.793 & 0.730 \\
Langmuir (LR) & $\mathrm{q}_{\max }\left(\mathrm{mmol} \mathrm{g}^{-1}\right)$ & 0.818 & 0.774 \\
& $\mathrm{~b}\left(\mathrm{Lmol}^{-1}\right)$ & 13.0 & 5.15 \\
& $\mathrm{R}^{2}\left(\mathrm{mmol} \mathrm{g}^{-1}\right)$ & 0.922 & 0.979 \\
Langmuir (NLR) & $\mathrm{q}_{\max }\left(\mathrm{mmol}^{-1}\right)$ & 0.742 & 0.765 \\
& $\mathrm{~b}\left(\mathrm{~L} \mathrm{mmon}^{2}\right.$ & 49.5 & 5.44 \\
Freundlich & $\mathrm{R}^{2}$ & 0.941 & 0.979 \\
& $\mathrm{k}_{\mathrm{F}}$ & 0.731 & 0.604 \\
Sips & $\mathrm{n}$ & 7.23 & 5.36 \\
& $\mathrm{R}^{2}$ & 0.899 & 0.979 \\
& $\mathrm{q}_{\max , \mathrm{S}}\left(\mathrm{mmol} \mathrm{g}^{-1}\right)$ & 1.510 & 0.913 \\
& $\mathrm{~b}_{\mathrm{S}}(\mathrm{L} \mathrm{mmol}$ & \\
& $\mathrm{n}_{\mathrm{S}}$ & 0.950 & 2.177 \\
& $\mathrm{R}^{2}$ & 4.15 & 1.71 \\
& 0.700 & 0.938 \\
\hline
\end{tabular}

$\left(\mathrm{R}^{2}\right.$ : determination coefficient calculated on the comparison of experimental data to simulated data - not on linearized data) (Experimental conditions: $\mathrm{pH}$ : 5.10; T: $26^{\circ} \mathrm{C}$; SD: $0.4 \mathrm{~g} \mathrm{~L}^{-1}$; Time: $4 \mathrm{~h}$ ).

profiles are very close for the two metal ions, it is thus possible anticipating difficulties in separating the two metals from multicomponent solutions; this is addressed below. The chemistry of the two metals are very similar and the softness parameter is relatively close for La(III) (i.e., - 0.75) and for Y(III) (i.e., -0.69) [68]. These metal ions can be ranked among the hard acids; according to the hard and soft acid and base theory (HSAB, or Pearson's rules) they will preferentially react with hard bases such as organic phosphorous compounds [70,71]. This can explain the affinity of the aminophosphonate-based sorbent for $\mathrm{Y}$ (III) and La(III), while their close chemical properties may limit their selective separation.

The dimensionless parameter, $\mathrm{R}_{\mathrm{L}}$, also called separation factor, is obtained by: $R_{L}=1 /\left(1+b \cdot C_{o}\right)$, where $C_{o}$ is the initial concentration of the RE(III) ions. The values of $R_{L}$ provide information on the nature of the sorption process [69]; when $\mathrm{R}_{\mathrm{L}}=0$ the sorption is irreversible, while for $0<R_{L}<1$ the sorption is favorable. The case of $R_{L}=1$ is associated to a linear sorption system (Henry equation), while the sorption is considered unfavorable when $R_{L}>1$. The coefficient $R_{L}$ was calculated, at different initial concentrations, $\mathrm{R}_{\mathrm{L}}$ value lies between 0.03 and 0.29 for La(III), and between 0.06 and 0.43 for Y(III). These values are systematically below 1: this means that the sorption is favorable; in addition, the favorability increases with the metal concentration, tending to irreversible behavior at the highest concentrations.

Complementary tests performed at different temperatures allowed evaluating the thermodynamic parameters for $\mathrm{La}(\mathrm{III})$ and Y(III) binding on PPA-PGMA (Table 4). The sorption is endothermic (positive value of enthalpy change), spontaneous (negative value of Gibbs energy change) and entropically driven (positive value of entropy change). The Additional Material Section (Section IV, Figure AM IVa, b) shows a more detailed discussion of experimental data.

\subsubsection{Comparison of sorption properties with other sorbents}

Table 5 reports $\mathrm{La}(\mathrm{III})$, and Y(III) sorption capacities of different sorbents. Though the experimental conditions are not systematically identical (making thus the strict comparison difficult), these data demonstrate that PPA-PGMA has comparable sorption capacities for La (III) and Y(III) than most of the reported materials. Remarkable sorption levels were reported with polycarboxymethyl cellulose (PCM-cellulose) [60], activated carbon from rice husk [6] and grapefruit peel [11] in the case of La(III) removal, while in the case of Y(III) removal alginate-based materials (impregnated with organophosphonic extractant) were highly efficient [72].

\subsubsection{Sorption selectivity}

Previous experimentations (considering both $\mathrm{pH}$ effect, equilibrium and kinetics) show that La(III) and Y(III) have very close behaviors in terms of interactions with PPA-PGMA. The selective separation appears difficult to achieve. A complementary experiment was performed on binary equimolar La(III) and Y(III): the equimolar concentration was set at $2 \mathrm{mmol} \mathrm{L}^{-1}$; with SD: $0.4 \mathrm{~g} \mathrm{~L}^{-1}, \mathrm{pH}_{0}: 5.06$, T: $26^{\circ} \mathrm{C}$, contact time: $8 \mathrm{~h}$. At equilibrium, the sorption capacities for $\mathrm{La}(\mathrm{III})$ and $\mathrm{Y}(\mathrm{III})$ reach $0.50 \mathrm{mmol} \mathrm{La} \mathrm{g}^{-1}$ and $0.39 \mathrm{mmol} \mathrm{Y} \mathrm{g}^{-1}$, respectively. The cumulative sorption capacity is $0.89 \mathrm{mmol} \mathrm{g}^{-1}$ : this is about $10 \%$ higher than the maximum sorption capacity obtained for La(III) on mono-component sorption isotherm. This means that La(III) and Y(III) bind to the same reactive group $\left(-\mathrm{P}-\mathrm{O}^{-}\right)$but also that some other functional groups may also contribute to bind additional species at high metal concentration (including substituted amine groups). The distribution coefficients $\left(\mathrm{K}_{\mathrm{d}}=\mathrm{q}_{\mathrm{eq}} / \mathrm{C}_{\mathrm{eq}}\right)$ were determined for both $\mathrm{La}(\mathrm{III})$ and $\mathrm{Y}(\mathrm{III})$ for calculating the selectivity coefficient (SC): $\mathrm{SC}(\mathrm{La} / \mathrm{Y})=\mathrm{K}_{\mathrm{d}}(\mathrm{La})$ / $\mathrm{K}_{\mathrm{d}}(\mathrm{Y})$ : $\mathrm{SC}(\mathrm{La} / \mathrm{Y})$ tends to 1.31 , under selected experimental conditions. This means that the sorbent has a little preference for $\mathrm{La}(\mathrm{III})$ over Y(III); however, not enough for allowing the selective separation of the two metals. XPS (Fig. 4) and EDX (Fig. AM4, see AMS) analyses have confirmed the simultaneous sorption of the two metals and their homogeneous distribution at the surface of PPA-PGMA particles.

\subsubsection{Metal desorption and sorbent recycling}

The metal desorption from loaded sorbent is essential for the global balance and competitiveness of the process. Indeed, the elution of the support is an important step for the concentrating effect and the recovery of valuable metals, for the accumulation of hazardous metals. An efficient desorption also contributes to facilitating the re-use of the sorbent. For low-cost metals or for expensive sorbents, the recycling of the sorbent is imperative. A nitric acid solutions $(0.5 \mathrm{M})$ was selected for testing the desorption of $\mathrm{La}(\mathrm{III})$ and Y(III), on the basis of previous results obtained with different types of sorbents $[4,60,73,74]$. Table 6 reports the sorption/desorption performances for 6 successive cycles. Under comparable experimental conditions, the sorption efficiency progressively decreases; however, for $\mathrm{La}(\mathrm{III})$, the difference between the first and the last cycles is less than $7 \%$, while for $\mathrm{Y}(\mathrm{III})$, the loss is even lower (i.e., less than 5\%). On the other side, in terms of

Table 4

Thermodynamic parameters of La(III) and Y(III) ions sorption.

\begin{tabular}{|c|c|c|c|c|c|c|}
\hline Metal ion & Temp. (K) & $\Delta \mathrm{H}^{\circ}\left(\mathrm{kJ} \mathrm{mol}^{-1}\right)$ & $\Delta \mathrm{S}^{\circ}\left(\mathrm{J} \mathrm{mol} \mathrm{K}{ }^{-1}\right)$ & $\Delta \mathrm{G}^{\circ}\left(\mathrm{kJ} \mathrm{mol}^{-1}\right)$ & $\mathrm{T} \Delta \mathrm{S}^{\circ}\left(\mathrm{kJ} \mathrm{mol}^{-1}\right)$ & $\mathrm{R}^{2}$ \\
\hline \multirow[t]{4}{*}{ La(III) } & 299 & 5.97 & 115.1 & -28.47 & 34.432 & 0.987 \\
\hline & 308 & & & -29.50 & 35.468 & \\
\hline & 318 & & & -30.65 & 36.619 & \\
\hline & 328 & & & -31.80 & 37.770 & \\
\hline \multirow[t]{4}{*}{ Y(III) } & 299 & 5.68 & 105.04 & -25.74 & 31.423 & 0.993 \\
\hline & 308 & & & -26.68 & 32.368 & \\
\hline & 318 & & & -27.73 & 33.418 & \\
\hline & 328 & & & -28.79 & 34.468 & \\
\hline
\end{tabular}

Experimental conditions: $\mathrm{pH}$ : 5.01; $\mathrm{C}_{\mathrm{o}}: 200 \mathrm{mg} \mathrm{L}^{-1}$; Time: $4 \mathrm{~h}$; SD: $0.4 \mathrm{~g} \mathrm{~L}^{-1}$. 
Table 5

Comparison of La(III) and Y(III) sorption capacities for selected sorbents.

\begin{tabular}{|c|c|c|c|c|c|}
\hline Metal ion & Sorbent & $\mathrm{pH}$ & Time (min) & $\mathrm{q}_{\max .}\left(\mathrm{mmol} \mathrm{g}^{-1}\right)$ & Reference \\
\hline \multirow[t]{15}{*}{$\mathrm{La}(\mathrm{III})$} & Iron oxide loaded Ca-alginate beads & 2.3 & 1680 & 0.014 & {$[8]$} \\
\hline & & 3.5 & & 0.711 & \\
\hline & & 5 & & 0.859 & \\
\hline & Activated carbon from rice husk & 3.5 & 60 & 1.263 & {$[6]$} \\
\hline & Grapefruit peel & 5 & 60 & 1.233 & [11] \\
\hline & DTPA@ magnetite nanoparticles & 6 & 90 & 0.446 & [9] \\
\hline & Lewatit TP 207 resin & 3.6 & 30 & 0.821 & {$[75]$} \\
\hline & Lewatit TP 260 resin & 5.2 & 30 & 0.763 & \\
\hline & $\mathrm{SnO}_{2}-\mathrm{TiO}_{2} \mathrm{NCs}$ nanocomposites & 5 & 60 & 0.473 & {$[76]$} \\
\hline & Polydopamine /nanofibrous mats & 4.5 & 1440 & 0.429 & {$[35]$} \\
\hline & EHPNA loaded microcapsules & 3 & 10 & 0.137 & {$[72]$} \\
\hline & PAC-Cellulose & 5 & 180 & 0.730 & {$[60]$} \\
\hline & PCM-Cellulose & & & 1.225 & \\
\hline & Cellulose-Zn/Al LDH nanocomposite & 7 & 10 & 0.666 & {$[5]$} \\
\hline & PPA-PGMA & 5 & 240 & 0.789 & This work \\
\hline \multirow[t]{6}{*}{ Y(III) } & Sodium alginate & 6 & 60 & 1.114 & [77] \\
\hline & Calcium alginate & & & 2.045 & \\
\hline & Nano Maghemite & 6.9 & 50 & 0.155 & {$[78]$} \\
\hline & $\left(\mathrm{CeO}_{2} \mathrm{CdO}\right)$ nanomaterials & 6 & 90 & 0.954 & [79] \\
\hline & Cellulose-Zn/Al LDH nanocomposite & 7 & 10 & 1.150 & {$[5]$} \\
\hline & PPA-PGMA & 5 & 240 & 0.733 & This work \\
\hline
\end{tabular}

Table 6

Metal desorption and sorbent recycling - Relative efficiencies.

\begin{tabular}{lllll}
\hline \multirow{2}{*}{ Cycle no. } & \multicolumn{2}{c}{ La(III) } & \multicolumn{3}{c}{ Y(III) } \\
\cline { 2 - 5 } & Sorption Eff. (\%) & Des. Eff. (\%) & Sorption Eff. (\%) & Des. Eff. (\%) \\
\hline 1 & $100^{*}$ & 97.75 & $100^{*}$ & 98.25 \\
2 & 96.79 & 97.22 & 97.69 & 98.02 \\
3 & 96.26 & 96.83 & 96.93 & 97.92 \\
4 & 95.73 & 95.73 & 95.58 & 96.98 \\
5 & 94.05 & 94.91 & 93.12 & 96.04 \\
6 & 93.41 & 94.24 & 95.20 & 95.35 \\
\hline
\end{tabular}

* Reference value for metal ion sorption efficiency (at first cycle). $\left(\mathrm{HNO}_{3}\right.$ : $0.5 \mathrm{M}$; T: $26^{\circ} \mathrm{C}$; SD: $0.8 \mathrm{~g} \mathrm{~L}^{-1}$; Time: $1 \mathrm{~h}$ ).

desorption, the changes in desorption efficiencies (DE) are less than 3\% for both La(III) and Y(III); for the 6 cycles, the DE is systematically above 94-95\%. At least with synthetic and pure solutions, the sorbent can be highly efficiently re-used. Fig. AM15 (see AMS) compares the FTIR spectra of the sorbent as produced and after five cycles of sorption and desorption. Though a complete element analysis was not carried out on the material, the very similar FTIR spectra indicate that the sorbent is stable. This is consistent with the stability of sorption performance.

\subsubsection{Test on ore leachates}

Section V (from Additional Material Section) describes the leaching of monazite ores (composition, process and characterization of leachates). Table 7 reports the concentrations of selected REEs and Y(III) in the $\mathrm{pH}$-controlled leachates (at $\mathrm{pH}$ 3.92), before and after sorption on PPA-PGMA. The sorption capacities are also reported in Table 7. The

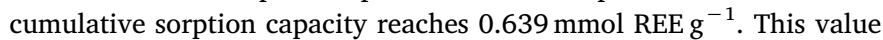
is lower than the maximum sorption capacities reported in Table 5 for PPA-PGMA, for the recovery of La(III) and Y(III) from synthetic solutions: $0.733 \mathrm{mmol} \mathrm{La} \mathrm{g}^{-1}$ and $0.789 \mathrm{mmol} \mathrm{Y} \mathrm{g}^{-1}$, respectively. Despite the complexity of the solution, the possible changes in the speciation of the metals (due to carbonate/bicarbonate salts), and the potential competitor effect of other heavy metals, the cumulative sorption capacity remains close to reference values (loss lower than 19\%). The second important question concerns the separation effect between light (from La to $\mathrm{Nd}$ ) and heavy REEs (from $\mathrm{Sm}$ to $\mathrm{Lu}$ ); due to very close chemical properties, $\mathrm{Y}$ is associated to HREEs. The study on synthetic solutions showed poor selectivity. This is confirmed for the treatment of

Table 7

Composition of the acid leachate of monazite ore and sorption of selected REEs using PPA-PGMA sorbent.

\begin{tabular}{|c|c|c|c|c|c|}
\hline REE Family & REE (III) & $\mathrm{C}_{\mathrm{o}}\left(\mathrm{mg} \mathrm{L}^{-1}\right)$ & $\mathrm{C}_{\mathrm{eq}}\left(\mathrm{mg} \mathrm{L}^{-1}\right)$ & $\mathrm{q}_{\mathrm{eq}}\left(\mathrm{mg} \mathrm{g}^{-1}\right)$ & $\mathrm{q}_{\mathrm{eq}}\left(\mu \mathrm{mol} \mathrm{g}^{-1}\right)$ \\
\hline \multirow[t]{5}{*}{ Light REEs } & $\mathrm{La}$ & 176.91 & 171.77 & 12.85 & 92.5 \\
\hline & $\mathrm{Ce}$ & 375.13 & 364.69 & 26.10 & 186.3 \\
\hline & $\mathrm{Pr}$ & 55.39 & 53.25 & 5.35 & 38.0 \\
\hline & $\mathrm{Nd}$ & 235.76 & 226.09 & 24.18 & 167.6 \\
\hline & $\mathrm{Sm}$ & 89.10 & 87.36 & 4.35 & 28.9 \\
\hline \multirow[t]{9}{*}{ Heavy REEs } & $\mathrm{Eu}$ & 5.72 & 5.19 & 1.33 & 8.8 \\
\hline & Gd & 108.25 & 106.33 & 4.80 & 30.5 \\
\hline & $\mathrm{Tb}$ & 0.58 & 0.49 & 0.23 & 1.4 \\
\hline & Dy & 81.26 & 80.45 & 2.03 & 12.5 \\
\hline & Ho & 15.29 & 14.76 & 1.33 & 8.1 \\
\hline & Er & 6.36 & 6.09 & 0.68 & 4.1 \\
\hline & $\mathrm{Yb}$ & 1.82 & 1.63 & 0.48 & 2.8 \\
\hline & $\mathrm{Lu}$ & 0.35 & 0.32 & 0.07 & 0.4 \\
\hline & $\mathrm{Y}$ & 137.30 & 135.26 & 5.10 & 57.4 \\
\hline$\Sigma$ & & & & & 639.2 \\
\hline
\end{tabular}

(Experimental conditions: $\mathrm{pH}=3.92$; $\mathrm{SD}=0.4 \mathrm{~g} \mathrm{~L}^{-1}$; time $=4 \mathrm{~h}$; temperature $=25 \pm 1{ }^{\circ} \mathrm{C}$; agitation speed $=200 \mathrm{rpm}$ ). 
monazite leachates. Fig. AM16 (see AMS) shows the relative percentages of the different REEs in the initial leaching liquor and in the two compartments (treated leachate and sorbent). The comparison of the percentages in the solution, before and after sorption, shows almost no change. This is a first confirmation that the sorbent has very limited selectivity. The percentages in the sorbent show little different trends; compared to initial composition of the leachate, there is a little enrichment in the solid phase for $\mathrm{Nd}$ (III) (from $17.2 \%$ to $26.2 \%$ ), and to a lesser extent for $\mathrm{La}$ (III) (from $13.4 \%$ to $14.5 \%$ ), Ce(III) (from $28.2 \%$ to $29.1 \%$ ) and $\operatorname{Pr}(\mathrm{III}$ ) (from $4.1 \%$ to $5.9 \%$ ). On the opposite hand, some REEs are depleted on the sorbent: mainly Y(III) (from $16.3 \%$ to $9.0 \%$ ), Sm(III) (from $6.2 \%$ to $4.5 \%$ ), Gd(III) (from $7.3 \%$ to $4.8 \%$ ), Dy(III) (from $5.3 \%$ to $2 \%$ ). The LREEs are little enriched in the sorbent while HREEs are weakly depleted. For the heaviest REEs (i.e., from Ho to $\mathrm{Lu},+\mathrm{Tb}$ ), the levels of concentration are very low and the variations in relative percentages are poorly significant. Fig. A M17 shows the correlations between the atomic number and the enrichment factor $(\mathrm{EF}=$ molar percentage on the sorbent/molar percentage in the leachate) and the distribution coefficient $\left(\mathrm{K}_{\mathrm{d}} ; \mathrm{q}_{\mathrm{eq}} / \mathrm{C}_{\mathrm{eq}}\right)$. These correlations are only considered for REEs having a molar percentage in the leachate superior to $1 \%$; for other elements, the low levels of concentration causes some discrepancies and dispersion in the calculation of the distribution coefficients. The fig ure shows clear trends: for LREEs the enrichment factor is superior to 1 and increases with atomic number, while HREEs (with enrichment factor lower than 1) show a reciprocal trend. Obviously, yttrium falls out from the linear curves: $\mathrm{Y}$ is usually associated to HREEs, because of its similar chemical properties, though its atomic number (i.e., 39) class this element out of the lanthanide series. In any case, the order of magnitude of the EF is of the same order of magnitude than for HREEs. The same conclusions are observed for the distribution coefficients, which are significantly higher for LREEs than for HREEs. PPA-PGMA has a little preference for LREEs over HREEs, but not enough for achieving effective separation. Actually, the comparison of the chemical properties of selected REEs (Table AM2, see AMS) shows that $\mathrm{Y}$ element is very similar to Dy and Ho elements, corresponding to atomic numbers 66 and 67, respectively. The shift of $Y$ point to its "analogous atomic number" falls clearly on the linear trends of the HREEs (Fig. AM17, see AMS). Fig. AM18 (see AMS) shows, for selected REEs (having significant m olar p ercentage), the c orrelation between the enrichment factor and either the electronegativity or the hydrated ionic radius of REEs. La and Ce elements are border elements with almost no change in the enrichment factor. For LREEs, the enrichment factor increases with electronegativity and decreases with increasing hydration ionic radius. The HREEs follow a reciprocal trend.

Egyptian monazite is essentially constituted of LREEs (i.e., Ce, La); the higher levels of their concentrations in the leachate also explain their higher percentages on the sorbent, close to $75.8 \%$, against $15.2 \%$ for HREEs and $9.0 \%$ for Y. In the leachate, these percentages were $63.0 \%, 20.7 \%$ and $16.3 \%$, respectively. This is consistent with previous conclusions on relative preference for LREEs.

\section{Conclusions}

Poly(glycidylmethacrylate) micro-particles were successfully functionalized, first with diethylenetriamine, and finally by N-methylphosphonation, to prepare a sorbent (PPA-PGMA). The sorbent is extensively characterized by a wide diversity of analytical methods (including thermogravimetric analysis, FTIR, SEM and SEM-EDX analyses, XPS analysis, elemental titration and acid-base titration) to confirm the successive modifications and more specifically the grafting of amino-methylphosphonic acid groups. Molecular modeling helps for the interpretation of the interactions of metal ions mainly with phosphonate-based moieties, though amine groups may also contribute, as a complement to physicochemical tools.

The sorbent is highly efficient for the sorption of La(III) and Y(III), at $\mathrm{pH}_{0}$ close to 5 (equilibrium $\mathrm{pH}$ value close to 3.3-3.5). The mechanisms involved in metal binding depend on the $\mathrm{pH}$, the protonation of reactive groups and the surface charge of the polymer. At the optimum $\mathrm{pH}$ (higher than the $\mathrm{pH}_{\mathrm{PzC}}$ : 2.69) the most reactive groups are the $\mathrm{O}$ donor atom on phosphonate groups.

The sorption isotherms are fitted by the Langmuir equation; the maximum sorption capacities are very close for $\mathrm{La}(\mathrm{III})$ and Y(III) (i.e., $0.79 \mathrm{mmol} \mathrm{La} \mathrm{g}^{-1}$ and $0.73 \mathrm{mmol} \mathrm{Y} \mathrm{g}^{-1}$ ). The maximum sorption capacities and the affinity coefficients are of the same order of magnitude; this makes difficult the separation of the two metals (as confirmed by sorption test in bi-component solutions: $\mathrm{SC}(\mathrm{La} / \mathrm{Y})=1.38$ ). The sorption process is endothermic and spontaneous with increase in the randomness of the system.

Uptake kinetics are efficiently modeled using the pseudo-first order rate equation and the Crank equation (for modeling resistance to intraparticle diffusion): the effective diffusivity is $2-3$ orders of magnitude lower than the self-diffusivity of metal ions in water. The contact time for reaching the equilibrium ranges between 3 and $4 \mathrm{~h}$, under selected experimental conditions.

Metal-loaded can be regenerated, over 6 cycles of sorption-desorption, using $0.5 \mathrm{M} \mathrm{HNO}_{3}$ solutions for metal desorption. The sorption and desorption efficiencies decrease by less than $7 \%$ at the sixth cycle. This makes PPA-PGMA a very promising sorbent. The sorbent was successfully tested for metal recovery from monazite leachates; however, it was not possible selectively separating the REEs: the little preference for LREEs is not sufficient for achieving their separation from HREEs.

\section{Acknowledgements}

This work was supported by the Hosei International Fund (HIF) (Japan) for financial support. Special dedication to the memory of Prof. Dr. Ahmed Donia. The authors acknowledge Prof. Enrique CastellonRodriguez (University of Malaga) for his help in the interpretation of XPS spectra.

\section{Appendix A. Supplementary data}

Supplementary data to this article can be found online at https:// doi.org/10.1016/j.cej.2019.121932.

\section{References}

[1] K. Binnemans, P.T. Jones, B. Blanpain, T. Van Gerven, Y. Yang, A. Walton, M. Buchert, Recycling of rare earths: a critical review, J. Cleaner Prod. 51 (2013) $1-22$.

[2] S. Cotton, Lanthanide and Actinide Chemistry, Chichester, UK, John Wiley \& Sons Ltd, 2006, p. 263.

[3] A.A. Galhoum, A.A. Atia, M.G. Mahfouz, S.T. Abdel-Rehem, N.A. Gomaa, T. Vincent, E. Guibal, Dy(III) recovery from dilute solutions using magnetic-chitosan nano-based particles grafted with amino acids, J. Mater. Sci. 50 (2015) 2832-2848.

[4] A.A. Galhoum, M.G. Mahfouz, S.T. Abdel-Rehem, N.A. Gomaa, A.A. Atia, T. Vincent, E. Guibal, Diethylenetriamine-functionalized chitosan magnetic nanobased particles for the sorption of rare earth metal ions Nd(III), Dy(III) and Yb(III), Cellulose 22 (2015) 2589-2605.

[5] S. Iftekhar, V. Srivastava, M. Sillanpaa, Synthesis and application of LDH intercalated cellulose nanocomposite for separation of rare earth elements (REEs), Chem. Eng. J. 309 (2017) 130-139.

[6] N.S. Awwad, H.M.H. Gad, M.I. Ahmad, H.F. Aly, Sorption of lanthanum and erbium from aqueous solution by activated carbon prepared from rice husk, Colloids Surf. B 81 (2010) 593-599.

[7] A.A. Galhoum, M.G. Mahfouz, A.A. Atia, S.T. Abdel-Rehem, N.A. Gomaa, T. Vincent, E. Guibal, Amino acid functionalized chitosan magnetic nanobased particles for uranyl sorption, Ind. Eng. Chem. Res. 54 (2015) 12374-12385.

[8] D. Wu, J. Zhao, L. Zhang, Q. Wu, Y. Yang, Lanthanum adsorption using iron oxide loaded calcium alginate beads, Hydrometallurgy 101 (2010) 76-83.

[9] S.d.N. Almeida, H.E. Toma, Neodymium(III) and lanthanum(III) separation by magnetic nanohydrometallurgy using DTPA functionalized magnetite nanoparticles, Hydrometallurgy 161 (2016) 22-28.

[10] A.A. Galhoum, K.M. Hassan, O.A. Desouky, A.M. Masoud, T. Akashi, Y. Sakai, E. Guibal, Aspartic acid grafting on cellulose and chitosan for enhanced Nd(III) sorption, React. Funct. Polym. 113 (2017) 13-22.

[11] M. Torab-Mostaedi, M. Asadollahzadeh, A. Hemmati, A. Khosravi, Biosorption of 
lanthanum and cerium from aqueous solutions by grapefruit peel: equilibrium, kinetic and thermodynamic studies, Res. Chem. Intermed. 41 (2013) 559-573.

[12] M. Benaglia, A. Alberti, L. Giorgini, F. Magnoni, S. Tozzi, Poly(glycidyl methacrylate): a highly versatile polymeric building block for post-polymerization modifications, Polym. Chem. 4 (2013) 124-132.

[13] X. Sun, L. Yang, H. Xing, J. Zhao, X. Li, Y. Huang, H. Liu, Synthesis of polyethylenimine-functionalized poly(glycidyl methacrylate) magnetic microspheres and their excellent Cr(VI) ion removal properties, Chem. Eng. J. 234 (2013) 338-345.

[14] S. Zafar, M.I. Khan, M. Khraisheh, S. Shahida, N. Khalid, M.L. Mirza, Effective removal of lanthanum ions from aqueous solution using rice husk: impact of experimental variables, Desalin. Water Treat. 132 (2018) 263-273.

[15] Q. Zhou, H. Yang, C.J. Yan, W.J. Luo, X.J. Li, J.J. Zhao, Synthesis of carboxylic acid functionalized diatomite with a micro-villous surface via UV-induced graft polymerization and its adsorption properties for lanthanum(III) ions, Colloids Surf. A 501 (2016) 9-16.

[16] A.R. Elsalamouny, O.A. Desouky, S.A. Mohamed, A.A. Galhoum, E. Guibal, Uranium and neodymium biosorption using novel chelating polysaccharide, Int. J. Biol. Macromol. 104 (2017) 963-968.

[17] A.A. Galhoum, M.G. Mahfouz, N.A. Gomaa, S.S. Abdel-Rehem, A.A. Atia, T. Vincent, E. Guibal, Cysteine-functionalized chitosan magnetic nano-based particles for the recovery of uranium(VI): uptake kinetics and sorption isotherms, Sep. Sci. Technol. 50 (2015) 2776-2789.

[18] D. Gomes Rodrigues, S. Monge, S.P. Pellet-Rostaing, N. Dacheux, D. Bouyer, C. Faur, Sorption properties of carbamoylmethylphosphonated-based polymer combining both sorption and thermosensitive properties: new valuable hydrosoluble materials for rare earth elements sorption, Chem. Eng. J. 355 (2019) $871-880$.

[19] E.A. Imam, I. El-Tantawy El-Sayed, M.G. Mahfouz, A.A. Tolba, T. Akashi, A.A. Galhoum, E. Guibal, Synthesis of $\alpha$-aminophosphonate functionalized chitosan sorbents: effect of methyl vs phenyl group on uranium sorption, Chem. Eng. J. 352 (2018) 1022-1034.

[20] E.-R.S. Kenawy, M.M. Azaam, K.M. Saad-Allah, Synthesis and antimicrobial activity of $\alpha$-aminophosphonates containing chitosan moiety, Arabian J. Chem. 8 (2015) 427-432.

[21] A.A. El Gokha, A.A.S. Ahmed, N.A.M. Abdelwahed, I.E.-T. El Sayed, Synthesis and antimicrobial activity of novel mono- and bis- $\alpha$-aminophosphonate derivatives, Int. J. Pharm. Sci. Rev. Res. 36 (2016) 35-39.

[22] D. Kolodynska, P. Rudnicki, Z. Hubicki, New approach to Cu(II), Zn(II) and Ni(II) ions removal at high $\mathrm{NaCl}$ concentration on the modified chelating resin, Desalin. Water Treat. 74 (2017) 184-196.

[23] Z. Wang, P. Yin, Z. Wang, R. Qu, X. Liu, Chelating resins silica gel supported aminophosphonic acids prepared by a heterogeneous synthesis method and a homogeneous synthesis method and the removal properties for $\mathrm{Hg}(\mathrm{II})$ from aqueous solutions, Ind. Eng. Chem. Res. 51 (2012) 8598-8607.

[24] B. Maranescu, A. Popa, L. Lupa, V. Maranescu, A. Visa, Use of chitosan complex with aminophosphonic groups and cobalt for the removal of $\mathrm{Sr}^{2+}$ ions, Sep. Sci. Technol. 53 (2018) 1058-1064.

[25] G. Xu, L. Wang, Y.J. Xie, M.L. Tao, W.Q. Zhang, Highly selective and efficient adsorption of $\mathrm{Hg}^{2+}$ by a recyclable aminophosphonic acid functionalized polyacrylonitrile fiber, J. Hazard. Mater. 344 (2018) 679-688.

[26] C.M. Davidescu, M. Ciopec, A. Negrea, A. Popa, L. Lupa, E.S. Dragan, R. Ardelean, G. Ilia, S. Iliescu, Synthesis, characterization, and Ni(II) ion sorption properties of poly(styrene-co-divinylbenzene) functionalized with aminophosphonic acid groups, Polym. Bull. 70 (2013) 277-291.

[27] Y. Sasaki, T. Oshima, Y. Baba, Mutual separation of indium(III), gallium(III) and zinc(II) with alkylated aminophosphonic acids with different basicities of amine moiety, Sep. Purif. Technol. 173 (2017) 37-43.

[28] H. Hou, J. Xu, Y. Wang, J. Chen, Solvent extraction of lanthanum and cerium ions from hydrochloric acidic aqueous solutions using partly saponified 2-ethylhexyl phosphonic acid mono-2-ethylhexyl ester, Chin. J. Chem. Eng. 24 (2016) 79-85.

[29] X. Huang, J. Dong, L. Wang, Z. Feng, Q. Xue, X. Meng, Selective recovery of rare earth elements from ion-adsorption rare earth element ores by stepwise extraction with HEH(EHP) and HDEHP, Green Chem. 19 (2017) 1345-1352.

[30] Z. Sun, D. Chen, B. Chen, L. Kong, M. Su, Enhanced uranium(VI) adsorption by chitosan modified phosphate rock, Colloids Surf. A 547 (2018) 141-147.

[31] H.N.A. Hassan, M.E.M. Hassouna, Simultaneous microdetermination of carbon, hydrogen, phosphorus and chlorine or bromine in organic compounds and some pharmaceutical preparations, Egyptian J. Pharm. Sci. 34 (1993) 445-454.

[32] M.E.M. Hassouna, H.N.A. Hassan, One step oxygen flask-spectrophotometric method for the micro and submicro-determination of phosphorus in organophosphorus compounds, Egyptian J. Chem. 37 (1994) 615-626.

[33] S. Saber-Samandari, S. Saber-Samandari, S. Heydaripour, M. Abdouss, Novel carboxymethyl cellulose based nanocomposite membrane: synthesis, characterization and application in water treatment, J. Environ. Manage. 166 (2016) 457-465.

[34] M.R. Yazdani, E. Virolainen, K. Conley, R. Vahala, Chitosan-zinc(II) complexes as a bio-sorbent for the adsorptive abatement of phosphate: mechanism of complexation and assessment of adsorption performance, Polymers 10 (2018).

[35] G. Hong, L. Shen, M. Wang, Y. Yang, X. Wang, M. Zhu, B.S. Hsiao, Nanofibrous polydopamine complex membranes for adsorption of lanthanum (III) ions, Chem. Eng. J. 244 (2014) 307-316.

[36] A.D. Becke, Density-functional thermochemistry. 3. The role of exact exchange, J. Chem. Phys. 98 (1993) 5648-5652.

[37] C.T. Lee, W.T. Yang, R.G. Parr, Development of the Colle-Salveti correlation-energy formula into a functional of the electron-density, Phys. Rev. B: Condens. Matter 37 (1988) 785-789.
[38] P.J. Stephens, F.J. Devlin, C.F. Chabalowski, M.J. Frisch, Ab-initio calculation of vibrational absorption and circular-dichroism spectra using density-functional force-fields, J. Phys. Chem. 98 (1994) 11623-11627.

[39] P.J. Hay, W.R. Wadt, Ab initio effective core potentials for molecular calculations-potentials for K to Au including the outermost core orbitals, J. Chem. Phys. 82 (1985) 299-310.

[40] G.A. Zhurko, D.A. Zhurko, Chemcraft-graphical software for visualization of quantum chemistry computations, Version 1.7 (build 382), Access: https://www. chemcraftprog.com, 2013.

[41] M.J. Frisch, D.W. Trucks, H.B. Schlegel, G.E. Scuseria, M.A. Robb, J.R. Cheeseman, J.A.J. Montgomery, T. Vreven, K.N. Kudin, J.C. Burant, et al., Gaussian 03. A quantum Chemistry Package, Gaussian Inc., Wallingford, CT (USA), 2004.

[42] V.M. Ramos, N.M. Rodriguez, M.F. Diaz, M.S. Rodriguez, A. Heras, E. Agullo, Nmethylene phosphonic chitosan. Effect of preparation methods on its properties, Carbohydr. Polym. 52 (2003) 39-46.

[43] Z.Q. Song, W.E. Baker, Chemical-reactions and reactivity of primary, secondary and tertiary diamines with acid acid functionalized polymers, J. Polym. Sci., Part A: Polym. Chem. 30 (1992) 1589-1600.

[44] Z.Q. Wei, Z. Wang, R.Y. Hong, Y.F. Wang, Monodisperse plum-like sulfonated PGMA-DVB microspheres as a new ion exchange resin, J. Appl. Polym. Sci. 134 (2017).

[45] M. Imperiyka, A. Ahmad, S.A. Hanifah, F. Bella, A UV-prepared linear polymer electrolyte membrane for dye-sensitized solar cells, Physica B 450 (2014) 151-154.

[46] T. Caykara, F. Cakar, S. Demirci, A new type of poly(glycidyl methacrylate) microbeads with surface grafted iminodiacetic acid: synthesis and characterization, Polym. Bull. 61 (2008) 311-318.

[47] E.T. Rochow, L. Haussler, A. Korwitz, D. Pospiech, Thermal decomposition of phosphonate-containing methacrylate-based copolymers, Polym. Degrad. Stab. 152 (2018) 235-243.

[48] L. Lv, J. Zhang, S. Yuan, L. Huang, S. Tang, B. Liang, S.O. Pehkonen, Enhanced adsorption of $\mathrm{Cu}(\mathrm{II})$ ions on chitosan microspheres functionalized with polyethylenimine-conjugated poly(glycidyl methacrylate) brushes, RSC Adv. 6 (2016) 78136-78150.

[49] W. Wang, Q. Zhang, B. Zhang, D. Li, X. Dong, L. Zhang, J. Chang, Preparation of monodisperse, superparamagnetic, luminescent, and multifunctional PGMA microspheres with amino-groups, Chin. Sci. Bull. 53 (2008) 1165-1170.

[50] Y. Tang, Q. Ma, Y. Luo, L. Zhai, Y. Che, F. Meng, Improved synthesis of a branched poly(ethylene imine)-modified cellulose-based adsorbent for removal and recovery of Cu(II) from aqueous solution, J. Appl. Polym. Sci. 129 (2013) 1799-1805.

[51] Y.V. Bondar, H.J. Kim, Y.J. Lim, Sulfonation of (glycidyl methacrylate) chains grafted onto nonwoven polypropylene, J. Appl. Polym. Sci. 104 (2007) 3256-3260.

[52] C. Liu, R. Bai, L. Hong, Diethylenetriamine-grafted poly(glycidyl methacrylate) adsorbent for effective copper ion adsorption, J. Colloid Interface Sci. 303 (2006) 99-108.

[53] J. Coates, Interpretation of infrared spectra, a practical approach, in: R.A. Meyers (Ed.), Encyclopedia of Analytical Chemistry, John Wiley \& Sons Ltd, Chichester, U.K., 2000, pp. 10815-10837.

[54] M.C. Zenobi, C.V. Luengo, M.J. Avena, E.H. Rueda, An ATR-FTIR study of different phosphonic acids adsorbed onto boehmite, Spectrochim. Acta, Part A 75 (2010) 1283-1288.

[55] A. Popa, R. Ene, D. Visinescu, E.S. Dragan, G. Ilia, S. Iliescu, V. Parvulescu, Transitional metals immobilized by coordination on aminophosphonate functionalized copolymers and their catalytic properties, J. Mol. Catal. A 408 (2015) 262-270.

[56] R. Williams, pKa data (compiled by R. Williams), http://www.chem.wisc.edu/ areas/reich/pkatable/pKa_compilation-1-Williams.pdf, Accessed: 4/6/2017.

[57] T.J.M. Fraga, L.E.M. de Lima, Z.S.B. de Souza, M.N. Carvalho, E.M.P.d.L. Freire, M.G. Ghislandi, M.A. da Motta, Amino- $\mathrm{Fe}_{3} \mathrm{O}_{4}$-functionalized graphene oxide as a novel adsorbent of Methylene Blue: kinetics, equilibrium, and recyclability aspects, Environ. Sci. Pollut. Res. Int. (2018).

[58] J. Viveros-Ceballos, M. Ordóñez, F. Sayago, C. Cativiela, Stereoselective synthesis of a-amino-C-phosphinic acids and derivatives, Molecules 21 (2016) 1141.

[59] M. Sahin, N. Kocak, G. Arslan, H.I. Ucan, Synthesis of crosslinked chitosan with epichlorohydrin possessing two novel polymeric ligands and its use in metal removal, J. Inorg. Organomet. Polym. Mater. 21 (2011) 69-80.

[60] A.A. Tolba, S.I. Mohamady, S.S. Hussin, T. Akashi, Y. Sakai, A.A. Galhoum, E. Guibal, Synthesis and characterization of poly(carboxymethyl)-cellulose for enhanced La(III) sorption, Carbohydr. Polym. 157 (2017) 1809-1820.

[61] G. McKay, M.S. Otterburn, J.A. Aga, Intraparticle diffusion process occuring during adsorption of dyestuffs, Water Air Soil Pollut. 36 (1987) 381-390.

[62] H. Qiu, L. Lv, B. Pan, Q. Zhang, W. Zhang, Q. Zhang, Review: critical review in adsorption kinetic models, J. Zhejiang Univ. Sci. A 10 (2009) 716-724.

[63] W.J. Weber, J.C. Morris, Kinetics of adsorption on carbon from solutions, J. Sanitary Eng. Div. ASCE 89 (1963) 31-60.

[64] J.D. Merrifield, W.G. Davids, J.D. MacRae, A. Amirbahman, Uptake of mercury by thiol-grafted chitosan gel beads, Water Res. 38 (2004) 3132-3138.

[65] M. Garmsiri, H.R. Mortaheb, Enhancing performance of hybrid liquid membrane process supported by porous anionic exchange membranes for removal of cadmium from wastewater, Chem. Eng. J. 264 (2015) 241-250.

[66] M.M. Zhu, P. Fuks, G. Carta, Protein adsorption in anion exchange resins-effects of polymer grafting, support structure porosity, and protein size, J. Chem. Technol. Biotechnol. 93 (2018) 1948-1958.

[67] I. Persson, Hydrated metal ions in aqueous solution: how regular are their structures? Pure Appl. Chem. 82 (2010) 1901-1917.

[68] Y. Marcus, Ion Properties, Marcel Dekker Inc, New York, NY, 1997, p. 259.

[69] K.Y. Foo, B.H. Hameed, Insights into the modeling of adsorption isotherm systems, 
Chem. Eng. J. 156 (2010) 2-10.

[70] Y.J. Yang, S.D. Alexandratos, Affinity of polymer-supported reagents for lanthanides as a function of donor atom polarizability, Ind. Eng. Chem. Res. 48 (2009) 6173-6187.

[71] P.P. Yang, Q. Liu, J.Y. Liu, R.R. Chen, R.M. Li, X.F. Bai, J. Wang, Highly efficien immobilization of uranium(VI) from aqueous solution by phosphonate-functionalized dendritic fibrous nanosilica (DFNS), J. Hazard. Mater. 363 (2019) 248-257.

[72] E. Karnio, Y. Fujiwara, M. Mats Urnoto, F. Valenzuela, K. Kondo, Investigation on extraction rate of lanthanides with extractant-impregnated microcapsule, Chem. Eng. J. 139 (2008) 93-105.

[73] M.C. Palmieri, B. Volesky, O. Garcia, Biosorption of lanthanum using Sargassum fluitans in batch system, Hydrometallurgy 67 (2002) 31-36.

[74] K. Vijayaraghavan, M. Sathishkumar, R. Balasubramanian, Biosorption of lanthanum, cerium, europium, and ytterbium by a brown marine alga, Turbinaria conoides, Ind. Eng. Chem. Res. 49 (2010) 4405-4411.
[75] B. Esma, A. Omar, D.M. Amine, Comparative study on lanthanum(III) sorption onto Lewatit TP 207 and Lewatit TP 260, J. Radioanal. Nucl. Chem. 299 (2014) 439-446.

[76] M.M. Rahman, S.B. Khan, H.M. Marwani, A.M. Asiri, $\mathrm{SnO}_{2}-\mathrm{TiO}_{2}$ nanocomposites as new adsorbent for efficient removal of $\mathrm{La}(\mathrm{III})$ ions from aqueous solutions, J. Taiwan Inst. Chem. Eng. 45 (2014) 1964-1974.

[77] M. Khotimchenko, V. Kovalev, E. Khozhaenko, R. Khotimchenko, Removal of yt trium (III) ions from water solutions by alginate compounds, Int. J. Environ. Sci. Technol. 12 (2015) 3107-3116.

[78] S.S. Dubey, S. Grandhi, Sorption studies of yttrium(III) ions on surfaces of nanothorium(IV) oxide and nano-zirconium(IV) oxide, Int. J. Environ. Sci. Technol. 16 (2016) 59-70.

[79] H.M. Marwani, E.M. Bakhsh, S.B. Khan, E.Y. Danish, A.M. Asiri, Cerium oxide cadmium oxide nanomaterial as efficient extractant for yttrium ions, J. Mol. Liq. 269 (2018) 252-259. 